Preprints of the

Max Planck Institute for

Research on Collective Goods

Bonn 2007/11b

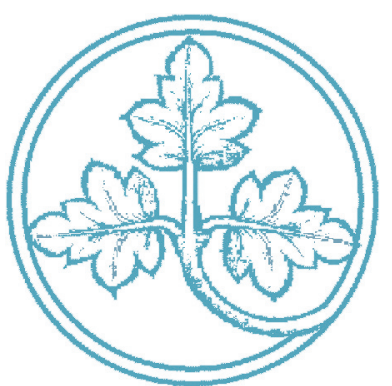

The aggregate and the representation of its parts

Axel Ostmann

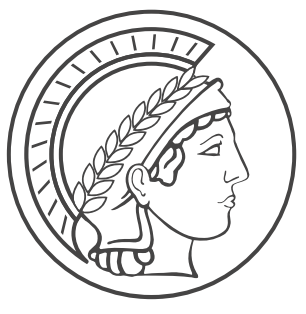




\title{
The aggregate and the representation of its parts
}

\author{
Axel Ostmann
}

October 2006 
The aggregate and the representation of its parts

Axel Ostmann*

October 2006

*AfOK, Saarbrücken, Germany, e-mail: a.ostmann@mx.uni-saarland.de 


\section{CONTENTS}

1 Introduction 3

2 Prologue: A mathematician establishes a societal calculus 3

3 The logical calculus $\quad 5$

3.1 Rules and simple games . . . . . . . . . . . . . . . . . . . . . 5

3.2 Criteria that may be met by rules of aggregation $\ldots \ldots \ldots \ldots \ldots$

3.3 Solutions for stand-offs $\ldots \ldots \ldots \ldots \ldots \ldots \ldots$

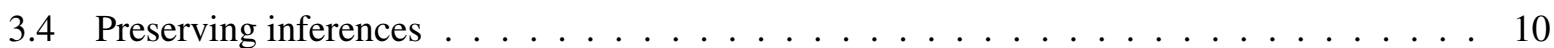

4 Domains of alternatives and judgements of preference 13

4.1 Borda und Condorcet . . . . . . . . . . . . . . . . . . . . . . . . . . 13

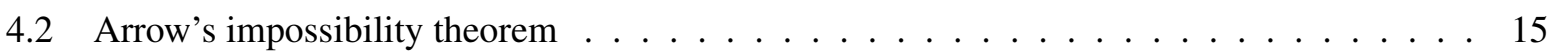

4.3 Structures admitting proper aggregates $\ldots \ldots \ldots \ldots \ldots \ldots \ldots$

4.4 Rules that are stable against stategic acts . . . . . . . . . . . . . . . . . . 17

5 Access to truth - a calculus of probabilities 20

6 Add-on simple games 22

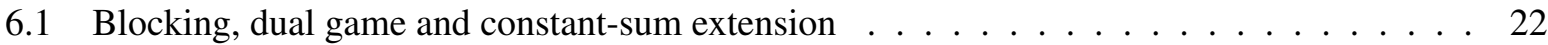

6.2 Composed games und Post's classes . . . . . . . . . . . . . . . . . . . . 22

6.3 Ressources and processes of production $\ldots \ldots \ldots \ldots \ldots \ldots$

7 Aggregation and representation $\quad 25$

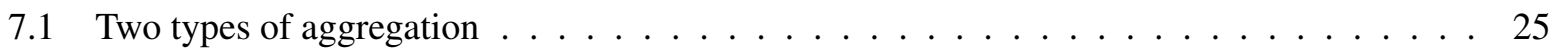

7.2 Representative, representances and representation . . . . . . . . . . . . . 26



7.4 Representative committees and minimal representations . . . . . . . . . . . . . . . . 28 


\section{INTRODUCTION}

The main concern of this contribution is to review the approach Condorcet applied to problems of aggregation and representation. The modern viewpoint usually chosen for these topic is mainly driven by social choice theory. Here the viewpoint was altered and the problems and solutions were presented in a setting which uses cooperative game theory.

After the introductory notes on Condorcet's basic ideas, we follow one logical path for an initial analysis of rules (Section 3). We present some new facts on the solutions to stand-offs. After connecting the logical appraoch and the social choice approach in Section 4, we discuss the probabilistic models introduced by Condorcet (Section 5). In Section 6 we provide additional structural insight, which can be derived from the game theoretic viewpoint. Based on the results of the previous sections, in Section 7 we analyse representation procedures. We develope a major tool for representation, namely the minimal representation of a weighted majority game. We discuss its construction and provide examples based on the results of the German Bundestag election in the year 2005.

\section{Prologue: A MATHEMATiCiAn ESTABLishes A SOCIETAL CALCUlus}

A maze - I try to recover the path Antoine Condorcet.

Marie Jean Antoine Nicolas Caritat Marquis de Condorcet was born in 1743. Despite his family's objection, he became a mathematician. Moreover, he became an astute publicist and participated in the two path-breaking endeavors of his time: the encyclopedia and the revolution. In 1769, he became a member of the Académie des Sciences. He designed a project of instruction publique, sketched out the constitution and the declaration of human rights. His uncompromising defense of human rights made him a "persona non grata" with both the "enlightened" sovereigns and with the revolutionaries. He was incarcerated three months before the murderous frenzy of the revolution ended. He died on March 30, 1794, in the prison of Bourg-la-Reine (Wahlster 1979).

As a mathematician, if one wants to separate this from today's perspective, Condorcet was a "geometer", as he used to call himself. He was an analysist and probability theorist, even though at that time these classifications would not have been used. However, Condorcet's characterisation by the historian of mathematics, Todhunter (Todhunter 1865), justifies this description (vgl. Granger 1956, Rashed 1974).

In its struggle for liberation against the clerical and secular domination, the Enlightenment had established how the world becomes explicable and manageable by reason-driven curiosity, through individual critique and libre examen. Mathematics already played an important rôle in this process. In particular, Condorcet's friend Turgot encouraged him to focus on topics relevant for society.

Finally, Condorcet developed the project mathématique sociale (Tableau général, Euvres, tome 1). This is nothing less than an attempt to integrate individual insights and demands into an interêt général that is able to support a development targeted at the bonheur public by preserving the "natural" individual rights. 
For our topic on aggregation and representation, we focus on a small part of this programme. This part mainly deals with voting procedures and elections. At Condorcet's time the demand for free and equal elections was a revolutionary one. The Tiers (i.e. people of the third rank) called for vôte par tête instead of vôte par ordre.

Condorcet was actively involved in the design of provincial assemblies (see the respective essay published in 1788) and of other decentralised committees for establishing participation.

Il suffira de répondre que tout homme a le droit de discuter publiquement des intérêts communs à tous les hommes. (Essai ..., Euvres, tome 8, p.119)

Condorcet gives priority to a process of public discussion and of democratisation, which he thinks should be carried out before holding elections for responsible representatives.

Il fallait donc affirmer les fondements de l'édifice avant de penser à en poser le comble. Avant de songer de donner des chefs aux citoyens, il fallait qu'il y eût des citoyens, il fallait qu'il y eût des citoyens en état de les choisir. (Vie de M. Turgot, Euvres, tome 5, p.142)

Only such representatives would pursue the interest of the whole and not their own interest or the interest of a (non-legitimated) group. They should behave as representatives in the true sense of the word and not as predators.

Condorcet criticised the American constitution. Here he rejected Locke's construct of natural justice, according to which the state is in essence no more than a guarantor of property and security. He demanded that the "truth of the human rights" become the base of all laws and of all administration (see Alexandre Koyre 1948). "Otherwise slaves would remain slaves."

The declaration of human rights is the necessary foundation for all politics that aims at the happiness of all members of the society. This claim also makes demands upon the individual; the intermediation of the wishes of society's members should be a rational process. Since humans by nature are inclined to solidarity and cooperation, if they fail jointly this must be due to conditions of inequality. Hence Condorcet demands the abolishment of slavery, equal rights for both sexes, property and education for everyone. Then:

Les révolutions amenées par le perfectionnement général de l'espèce humaine doivent sans doute la conduire à la raison et au bonheur. (Sur l'instruction publique, Euvres, tome 7, p. 186)

In order to balance interests, the "conditions" have to be shaped accordingly. The constitution and the election procedures are part of such a process. Individual reason has to be uplifted, a goal not in vain, since humans are perfectable.

In order to shape the conditions and to organise the balance of interests, people have to enter rational discourse. In large part this is a technique. Like others (Leibniz, or later Frege), Condorcet envisages the use of a langage universelle and its combinaisons and operations; we can interpret such a plan as a project of logic (Esquisse, p. 279-281).

... elle servirait à porter sur tous les objets qu'embrassent l'intélligence humaine, une rigueur, une précision qui rendraient la connaisance de la vérité facile et l'erreur presqu'impossible. (p. 281) 
Summing up: Favourable conditions being met, it is sufficient to apply logical calculus.

\section{THE LOGICAL CALCULUS}

\subsection{RULES AND SIMPLE GAMES}

In the long run a group $N$ of individuals $i$, making a joint decision, will face a question, which in the simplest case is about who agrees with a specific proposition $a$. The subset of all individuals agreeing with proposition $a$ is denoted by $[a]$. Correspondingly $\left[\begin{array}{ll}n o n & a\end{array}\right]$ denotes the subset of all individuals disagreeing.

Subsets of $N$ are called coalitions. The set $N$ itself is also called the grand coalition. If the group formally holds a ballot on some issue, then in most cases a rule is fixed beforehand, which determines what coalitions are considered sufficient to effectuate a common resolution.

Normally a decision rule has its "domain of validity", i.e. it is used only for a specific class of propositions. Within this domain of "admissible sentences", every individual can evaluate the proposition as "acceptable" and "true" or as "not acceptable" and "false", respectively.

Under the assumption that this domain is fixed, we can conceive of the rule as a specific coalitional game $^{1}$ called simple, that means, it is represented as a function assigning the value 1 or 0 to each coalition; a coalition gets the value 1 if it can effectuate a common resolution and it gets the value 0 if it can not do so. Then, with respect to a specific proposition $a$, the rule accepts it as "accepted by the group" and "judged as true by the group" if and only if the value of the coalition $[a]$ is 1 .

More formally: let the number of elements of a set $M$ be denoted by \# $M$. A simple game is a pair $(N, v), N$ being a finite set of size $n=\# N$, called a players' set, and $v$ a boolean function

$$
v: 2^{N} \rightarrow\{0,1\}: S \mapsto v(S)
$$

The binary notation of coalitions can ease some calculations. This is why, in the following, we do not distiguish between set- and vector-notations. In case of $N=\{1,2,3,4,5,6\}$, the subset $\{2,4,5\}$ will also be represented by $(0,1,0,1,1,0)$ or the simplifications 010110 and 245 . A coalition $S$ is called a winning coalition if $v(S)=1$; otherwise it is called losing.

Some of the rules are well known from everyday life:

\section{The unanimity rule}

$v(S)=1$ if and only if $S=N$.

2. The majority rule and absolute majority

$v(S)=1$ if and only if $\# S>n / 2$ and $\#[a]>\#[$ non $a]$ respectively.

In committees, corresponding rules often are given for the number of votes or shares instead of the number of members.

3. Rules of qualified majority

Here mainly majorities of $2 / 3$ or $3 / 4$ are in use.

\footnotetext{
${ }^{1}$ Sometimes coalitional games are called games in characteristic function form, a somewhat misleading notion because there is no well-defined entity "game" that can be represented in different forms.
} 
4. Rules of (qualified) majority enriched with a hedge clause

In most cases these rules are made to preserve the legitimate rights of minorities. An example is a voting rule that gives one vote to every province and accepts all majorities unless all southern provinces are voting against the proposal. Other examples are found in constitutions that include some guarantee for indigenious rights.

5. Rules that guarantee rights of minority and authorisations

A minority, say of $25 \%$ of the members of a parliament, may have the right to initiate a board of inquiry. In a firm, everybody of a specific hierarchical level may have the right to decide within the limits of specific budget; on another level, it may be necessary to get two signatures.

Looking at such rules it becomes evident that the specification of the domain of admissible propositions is an important task in the design of the rules.

\section{Rules of multiple qualifications}

Rules like those above in 4 and 5 can also be seen as special cases of multiple qualifications. Two widespread rules are the double qualification rules: "Both a majority of states and a majority of deputees" and "both the majority of votes and a majority of contributions."

Some of these rules - but not nearly all of them - can be represented by $n+1$ natural numbers. Then the unanimity rule can be written in short as $(n ; 1,1, \ldots, 1)$. More generally we set an individual voting weight $m_{i}$ for every individual $i$ and a voting threshold of $\lambda$. These data, these vectors $\left(\lambda ; m_{1}, \ldots, m_{i}, \ldots, m_{n}\right)$ generate what is known as the weighted majority games:

$$
v(S)=1 \text { if and only if } m(S) \geq \lambda \text {, setting } m(S)=\sum_{i \in S} m_{i}
$$

\subsection{CRITERIA THAT MAY BE MET BY RULES OF AGGREGATION}

In the following we discuss some properties that often are found as desirable for rules in order to produce an adequate aggregation. Since we represent a rule by a simple game and a domain of admissible sentences, these properties can be expressed as properties of the game and of the domain.

(1) $\mathrm{v}(\mathrm{N})=1$.

If all individuals agree upon a proposal, this proposal has to be accepted.

(2) $\mathrm{v}(\emptyset)=0$.

If no individual agrees upon a proposal, this proposal is rejected.

(3) Monotonicity

If coalition [a] is a winning coalition for a proposal a, additional individuals joining the coalition that backs the proposal should not prevent its acceptance. To state it formally, let $\mathrm{S}$ be a subset of $\mathrm{T}$. Then $\mathrm{v}(\mathrm{S})=1$ implies $v(T)=1$.

A coalition $S$ is called a minimal winning coalition or, in short, a min-win coalition if $v(S)=1$ and there is no winning coalition $\mathrm{T}$, such that $\mathrm{T}$ is contained in $\mathrm{S}$ and $\mathrm{T}$ is smaller than $\mathrm{S}$. In monotone games the function $\mathrm{v}$ is fully determined by the specification of all minimal winning coalitions. The set of all min-win coalitions is denoted by $\mathrm{M}=\mathrm{M}(\mathrm{v})=\mathrm{M}(\mathrm{N}, \mathrm{v})$. If monotonicity is assumed, then (1) can be replaced by the assumption that a winning coalition exists. The above introduced weighted majority games are monotone. 
(4) Symmetry and anonymity

There are circumstances where it is desirable to aggregate individual judgements so that each is weighted the same in the final judgement. The group's judgement should be independent from the reputation and status of the individuals, a property which sometimes is called anonymity. This claim can be specified in different ways. The strictest condition of such equal treatment is that applying any permutation ${ }^{2} \pi$ of the set $\mathrm{N}$ fixes the values of the coalitions, i.e. for all permutations $\pi$ and all coalitions $\mathrm{S}$, the equation $v(S)=v(\pi(S))$ is valid. Weaker versions of equal treatment will be considered below.

(5) Superadditivity and consistency

Should the domain of admissible sentences contain statements a and b, which are logically inconsistent and which cannot be true or fulfilled together, then - assuming individuals to act consistently - coalitions $[a]$ and $[b]$ are disjoint and have an empty intersection $[a] \cap[b]=\emptyset$. It is convenient to write $A+B$ instead of $A \cup B$ whenever $A$ and $B$ are disjoint.

In order that rules with domains rich enough to contain statements logically inconsistent determine a well-defined result, the respective games should have the property that every two winning coalitions have an non-empty intersection. Otherwise one coalition can determine a specific result and the other one, a result incompatible with the previous one. A game is called superadditive ${ }^{3}$ if and only if $v(S+T) \leq$ $v(S)+v(T)$. Since the maximal value of $v(S+T)$ is 1 , only one of two disjunctive coalitions can be a winning coalition. The property of superadditivity implies monotonicity. Rules like those above in 5 . (section 2.1) are not superadditive, but they are monotone. Superadditivity can be seen as a collective version of the law of non-contradiction.

(6) Constant-sum and "tertium non datur"

If the domain of admissible propositions entails any two contradictory statements, i.e. if either both proposition a and its negation non-a or neither of them are elements of the domain (we say, it is closed with respect to negation), then it is often preferred that one of them be accepted. In analogy to classical logic ("tertium non datur"), by such rules, stand-offs are avoided. The corresponding property is equivalent to the following formula: $v(S)+v(N-S)=1$ for all coalitions S. Such games are also called constant-sum simple games.

It is generally understood that for groups $\mathrm{N}$ with an even number of members, i.e. $\mathrm{n}=2 \mathrm{k}$, absolute majority, corresponding to the game with the representation $(\mathrm{k}+1 ; 1, \ldots, 1)$, is not a constant-sum game: a coalition of size $\mathrm{k}$ has a complement of the same size, which is not a winning coalition either. Similarly we learn that the game corresponding to absolute majority is constant-sum if the group is of odd size.

\footnotetext{
${ }^{2}$ A permutation of a (finite) set $\mathrm{N}$ is a one-to-one mapping $\pi: N \rightarrow N: i \mapsto \pi(i)$. For all i such that $i \neq \pi(i)$ the repeated application of $\pi$ will return to $i$ after $\# N$ steps at most: there is some $k=k(i) \in N$ such that $\pi^{k}(i)=i$. This is why we can represent a permutation by simply specifying its cycles. In the example \#N=5, (34) the permutation exchanges the element 3 and 4, and all other elements remain fixed. The permutation (13)(254) interchanges 1 and 3, and maps 2 to 5,5 to 4 , and 4 to 2 . The number of permutations is the same as the number of orderings on the respective set, i.e. \#N!.

Identifying the order $1>2>3>4>5$ with the identity (the mapping, fixing all elements), we can identify (13)(254) with $3>5>1>2>4$ and identify other orderings correspondingly.

Every permutation of $N$ also maps subsets $S \subset N$ on subsets, setting $\pi(S)=\{\pi(i) ; i \in S\}$. By the definition $(\pi(v))(S)=$ $v(\pi(S))$ the permutation can map games $(N, v)$ on games $(N, \pi(v))$.

${ }^{3}$ Shapley and other authors call a superadditive simple game "strong".
} 


\subsection{SOLUTIONS FOR STAND-OFFS}

As yet it is not clear whether there are any symmetric rules without stand-offs in case of even-sized groups. As reported by Ostmann (1993, p. 261), there is a symmetric constant-sum game for group size 6 . Let us examine how this example fits into the above framework.

Let $n=2 k=6$. Considering the rule of absolute majority, we have to add winning coalitions of size $k=3$ in a proper way. It is especially important to add half of the coalitions of size 3, respecting that for every added coalition $\mathrm{S}$, its opposition $\mathrm{N}-\mathrm{S}$ has to remain a losing coalition.

We claim that the following ten minimal winning coalitions generate a symmetric constant-sum game.

110001

011001

001101

000111

100011

110100

011010

101100

010110

101010

Summing up the entries of this ten-rows matrix columnwise, for every column we get the sum $r=5$. The property that for every individual we get the same number of minimal winning coalitions in which it is a member may be seen as a weak form of equal treatment (cp. property 3 ). Yet, in general, this property can neither guarantee that the game can be called symmetric nor that the number of winning coalitions each individual is a member in will be the same.

A permutation of $\mathrm{N}$, which preserves the game in the sense that every winning coalition is mapped to a winning coalition, and every losing coalition is mapped to a losing one, is called a symmetry of the game. ${ }^{4}$ Thus, the permutation $\pi$ is a symmetry of the game $(\mathrm{N}, \mathrm{v})$ if and only if $v=\pi(v)$ is valid.

We are now prepared to define an equal treatment condition that is stronger than the ones derived by pure counting and weaker than the strong condition given above in (4). It is given by the following:

Every individual can be mapped to any other one by a symmetry.

The significance of the property of equal treatment (in mathematics one speaks of a group acting transitively on the set $\mathrm{N}$ ) lies in the fact that every individual plays the same role in such a structure.

In the game given above, the permutations (12345) and (162)(453) are symmetries that generate the set of all symmetries by carrying out one after another repeatedly. ${ }^{5}$

\footnotetext{
${ }^{4}$ The symmetries form a subgroup of the group of all permutations. It is called the group of automorphisms of the game.

${ }^{5}$ Moreover, this group of automorphisms acts transitively on $\mathrm{N}$ in a twofold mannor, that means that an equal treatment of pairs is guaranteed. The construction of the game uses the means of projective geometry and is mentioned in Ostmann 1993, p. 261. This construction cannot be generalised in full. For reasons that are outlined in projective geometry and in the theory of fields, it becomes clear that the construction can only be done when $2 \mathrm{k}-1$ is a power of a prime. But in other cases it may be possible to reach the simple transitivity instead of the twofold transitivity - and this is fair enough for establishing an equal
} 
Given the above structure, with $\mathrm{N}$ as the point set and the 10 coalitions (called blocks), we get the structure of a special block design known as the Steiner-system $S_{2}(2,3 ; 6)$ (cp. Beth/Jungnickel/Lenz 1985 , p. 44, p. 614). In general, the sets of size $\mathrm{k}$ generate a complete block design, the trivial Steinersystem $S_{\lambda}(2, k ; 2 k)$ (cf. p.24) such that $\lambda=\left(\begin{array}{c}2 k-2 \\ k-2\end{array}\right) .6$ For $\mathrm{n}=6$ from every 4 coalitions of size $\mathrm{k}$ that contain a fixed pair of individuals, 2 coalitions are taken as winning.

It is easy to see that symmetry and the constant-sum property are not always compatible. ${ }^{7}$ In case of $\mathrm{n}=2$, establishing constant-sum requires that exactly one of the coalitions with one member is winning; however, this is incompatible with the symmetry condition. In case of $n=4$, we have to select 3 of the $\left(\begin{array}{l}4 \\ 2\end{array}\right)=6$ coalitions as winning. Because these three coalitions exhibit $3 \mathrm{k}=6$ memberships (usually called incidences), they cannot be equally distributed among the four players.

This argument can be generalised. If an individual is a member in $r$ winning coalitions of size $k$, then by symmetry every individual is member in $\mathrm{r}$ winning coalitions of size $\mathrm{k}$, resulting $\mathrm{in} \mathrm{nr}=2 \mathrm{kr}$ memberships (incidences) in total.

Proposition 3.1. Let $\# N=n=2 k$. For odd $\left(\begin{array}{c}2 k-1 \\ k-1\end{array}\right)$, there is no symmetric constant-sum game $(N, v)$.

Proof. The number of coalitions of size $\mathrm{k}$ is $\left(\begin{array}{c}2 k \\ k\end{array}\right)=\frac{2 k}{k} \frac{(2 k-1) !}{(k-1) ! k !}=2\left(\begin{array}{c}2 k-1 \\ k-1\end{array}\right)$. Thus we have to select $\left(\begin{array}{c}2 k-1 \\ k-1\end{array}\right)$ coalitions of size $\mathrm{k}$. Since each of these coalitions has $\mathrm{k}$ incidences, i.e. memberships, to equally distribute among the $2 \mathrm{k}$ individuals, the number $\left(\begin{array}{c}2 k-1 \\ k-1\end{array}\right)$ has to be an even number.

Table: the size of the first selections

\begin{tabular}{|c|c|c|c|c|c|c|c|c|c|c|c|}
\hline $\mathrm{n}$ & 2 & 4 & 6 & 8 & 10 & 12 & 14 & 16 & 18 & 20 & 22 \\
\hline \hline $\mathrm{k}$ & 1 & 2 & 3 & 4 & 5 & 6 & 7 & 8 & 9 & 11 & 12 \\
\hline$\left(\begin{array}{c}2 k-1 \\
k-1\end{array}\right)$ & 1 & 3 & 10 & 35 & 126 & 462 & 1716 & 6435 & 24.310 & 92.378 & 352.716 \\
\hline
\end{tabular}

From the table - and from applying the above proposition - we know that for $n=2,4,8,16$ there is no symmetric constant-sum game. This suggests a conjecture; namely, that there exists a symmetric constantsum game if and only if the number of individuals is not a power of two. The following proposition proves one part of this conjecture:

Proposition 3.2. Let $\# N=n=2 k$. The number $\left(\begin{array}{c}2 k-1 \\ k-1\end{array}\right)$ is odd if and only if $\# N=n=2^{s+1}$ for some number $s=0,1,2, \ldots$.

Proof. 1. Let $n=2^{s+1}$. We first show that $\left(\begin{array}{c}2^{s+1}-1 \\ 2^{s}-1\end{array}\right)$ is odd. We have

$$
\left(\begin{array}{c}
2^{s+1}-1 \\
2^{s}-1
\end{array}\right)=\prod\left\{\frac{2^{s}+i}{i} ; i=1, \ldots, 2^{s}-1\right\}
$$

treatment for individuals.

${ }^{6}$ Remember the definition $\left(\begin{array}{l}a \\ b\end{array}\right)=\frac{a !}{b !(a-b) !}$.

${ }^{7}$ Leaving the model and adding a probabilistic structure compatibility can be reached by rules like throwing a fair coin on which of the two parties (coalition and its opposition) is to determine the outcome. 
Splitting the product into two parts, one product collecting for odd numbers, the other one collecting for even numbers. In both parts we consider the factor

$$
\frac{2^{s}+i}{i}
$$

For odd i, both the denominator and the numerator are odd. For even i, we can reduce the fraction. We get:

$$
\frac{2^{r}+j}{j}, r<s, \text { and } \mathrm{j} \text { odd. }
$$

After reduction, all the factors of the above product are odd. Hence the expression itself is odd.

2. Now consider a case in which $\mathrm{n}$ is not a power of two. Then there exists a number $\mathrm{s}$ such that $2^{s}<n<2^{s+1}$. We shall prove that for all numbers $r<s$, the following is true:

There are at least as many numbers divisible by $2^{r}$ that are elements of the set $\mathrm{T}=\{\mathrm{k}+1, \mathrm{k}+2, \ldots, 2 \mathrm{k}-$ $1\}$ as that are elements of $\mathrm{S}=\{1,2, \ldots, \mathrm{k}-1\}$. Let $2^{r} i$ be the largest multiple of $2^{r}$ in the set $\mathrm{S}$. Then by $2^{r} i<k \leq 2^{r}(i+1)$, we get $2^{r}(2 i)<2 k=n \leq 2^{r}(2 i+2)$. Hence $\mathrm{S}$ contains i multiples of $2^{r}$, and $\mathrm{T}$ contains i or i+1 multiples of $2^{r}$.

Let us now reconsider the expression

$$
\left(\begin{array}{c}
2 k-1 \\
k-1
\end{array}\right)=\prod\left\{\frac{k+i}{i} ; i=1, \ldots, k-1\right\} .
$$

In the numerator we find the numbers of $\mathrm{T}$; in the denominator the numbers of $\mathrm{S}$. As we have proven, for each power of two smaller than $2^{s}$, the numerator contains at least as many numbers as the denominator. Hence we can reduce the fraction in such a way that the denominator becomes an odd number.

It remains to be shown that, after the reduction of the whole expression, the numerator becomes an even number. The only factor not yet reduced (with respect to division by two) is the factor of the maximal power of two, namely

$$
\frac{2^{s}}{2^{s}-k}
$$

Even after this factor is reduced, its numerator is an even number. Thus, $\left(\begin{array}{c}2 k-1 \\ k-1\end{array}\right)$ is an even number.

Remark. The property of monotonicity, together with a set of exactly $2^{n-1}$ winning coalitions ("halfhalf games"), does not guarantee the constant-sum property; the simplest counterexample is given by Shapley's game (p) (Shapley 1962). It will also be mentioned in section 5.2. This simplest game lacks symmetry indeed, but there are other more complicated examples (see Ostmann 1993).

\subsection{PRESERVING INFERENCES}

Statements can show further logical dependences besides inconsistency. If, for example, the expressions "if a then b" and "a" are true, then "b" is implied; moreover "a and b" is true. For the following let us specify what is to be understood under a logical aggregation. Under the general assumption of a classical two-valued logic, statements are evaluated as "true" or "false", which is expressed by the the "truth values" 1 and 0 respectively. Each individual of our group exposes such an evaluation. A rule of aggregation integrates all these individual judgements by applying the corresponding game $(\mathrm{N}, \mathrm{v})$. The aggregate judgment is "true" or "accepted" if and only if the coalition of individuals that evaluated the respective statement as true is a winning coalition. By this procedure, each statement substantiated with individual judgements gets its "collective truth value".

Without defining formally the domain of admissible sentences, we assume in the following that statements can be connected by the logical operations "non", "and", "or", "either - or", "if - then", "exactly then if", "neither - yet", "during". If all the new statements generated by these logical operations are admissible, we also speak of a domain closed with respect to logical operations. If the sentences con- 
tain variables like $\mathrm{a}$ and $\mathrm{b}$ above, the truth value of the whole sentence is a function of the truth values of the variables. Two sentences are logically equivalent if under all conditions they show the same truth value; this means that both truth functions coincide. Conventionally such functions are shown as truth tables. From the theory of logic it is well known that each formula generated as above is equivalent to an expression that contains only the two logical operations "non" and "if - then". 8

For example, the expression "a and b" is equivalent to "non (if a then (non b)".

If the domain of the statements contains at least two statements that are able to be substantiated freely, i.e. with judgements showing any possible pair of truth values, and if each statement produced with the operations "non" and "if - then" also belong to the domain, then all of the logical operations can be carried out and all the possible realisations of truth values can be generated.

A rule of aggregation is said to preserve the implication, if the truth table of the implication (i.e. the operation "if - then") of the aggregates coincides with the aggregate of the individual truth values of the "if - then" statements. The aggregate of the individual "if a, then b" statement is true if and only if the coalition [if $\mathrm{a}$, then $\mathrm{b}$ ] is a winning coalition. Assuming individual logical rationality, the coalition [if a, then $b$ ] is the union of the coalitions [(non a) and b], [a and (non b)] and [a and b].

Absolute majority rule does not preserve the implication. In order to construct a counter example, we assume the presence of only three opinions in the group. We consider the corresponding coalitions that internally exhibit identical opinions. Let $\mathrm{S}$ be a minimal winning coalition and let us choose an element $i \in S$. Then we set the following three coalitions as coalitions of identical opinions:

$$
S-\{i\},\{i\} \text {, and } N-S \text {. }
$$

None of them are winning. Every union of two of them is winning. Let $N-S$ accept three statements, a, b, c.; the coalition $S-\{i\}$ rejects b and c; the coalition $\{i\}$ rejects a and c. This is the content of the first 4 columns of the table. Evaluating the expression "if ( $a$ and $b$ ), then c" yields an unanimous judgement of acceptance. In contrast to this aggregate judgement, the logical consequence of the aggregate judgements on $\mathrm{a}, \mathrm{b}$, and $\mathrm{c}$ is a rejection of the expression "if ( $\mathrm{a}$ and $\mathrm{b}$ ), then $\mathrm{c}$ " ( $\mathrm{a}$ and $\mathrm{b}$ are evaluated as true, but $\mathrm{c}$ as false). In other words $[a]$ and $[b]$ and $[$ non $c]$ are winning coalitions. The last three columns of the table show the fact that the set $[(\mathrm{a}$ and $\mathrm{b})$, then $\mathrm{c}]$ equals $\mathrm{N}$. $\mathrm{N}$ is a winning coalition. Thus the fact that "(a and b), then c" is evaluated as true, contradicts the preservation of the implication.

\begin{tabular}{|c|c|c|c|c|c|c|}
\hline & $\mathrm{a}$ & $\mathrm{b}$ & $\mathrm{c}$ & non $\mathrm{c}$ & $\mathrm{a}$ and $\mathrm{b}$ & if $(\mathrm{a}$ and $\mathrm{b})$ then $\mathrm{c}$ \\
\hline \hline$S-\{i\}$ & 1 & 0 & 0 & 1 & 0 & 1 \\
\hline$\{i\}$ & 0 & 1 & 0 & 1 & 0 & 1 \\
\hline$N-S$ & 1 & 1 & 1 & 0 & 1 & 1 \\
\hline aggregate value & 1 & 1 & 0 & 1 & 0 & 1 \\
\hline
\end{tabular}

From the viewpoint of logic, the above discussed constant-sum property can be characterised as the preservation of the negation.

A rule that preserves both the negation and the implication respects all other logical operations too. ${ }^{9}$ A direct consequence of this is the following proposition:

Proposition 3.3. The game corresponding to a rule that preserves both the implication and the negation

\footnotetext{
${ }^{8}$ Indeed, there is also the single operation "not both", called the Sheffer stroke, which is enough to generate all formulas up to equivalence.

${ }^{9}$ It preserves the algebraic structure; one speaks of a logical homomorphism.
} 
(on a domain that is closed under logical operations) $)^{10}$ has the following property: If both $[a]$ and $[b]$ are winning coalitions, then $[a] \cap[b]$ is a winning coalition too.

By definition of $[],.[a] \cap[b]$ is equivalent to $[a$ and $b]$; the latter set is a winning coalition too, since the rule is preserving logical operations. In the following table we consider the four possible cases of different truth values for the expressions $a$ and $b$.

\begin{tabular}{|c|c|c|c|c|c|c|}
\hline statement & $\mathrm{a}$ & non $\mathrm{a}$ & $\mathrm{b}$ & non $\mathrm{b}$ & if a then $\mathrm{b}$ & $\mathrm{a}$ and $\mathrm{b}$ \\
\hline coalition & {$[\mathrm{a}]$} & {$[$ non $\mathrm{a}]$} & {$[\mathrm{b}]$} & {$[$ non $\mathrm{b}]$} & {$[$ if a then $\mathrm{b}]$} & {$[\mathrm{a}$ and $\mathrm{b}]$} \\
\hline \hline case 1 & 1 & 0 & 1 & 0 & 1 & 1 \\
\hline case 2 & 1 & 0 & 0 & 1 & 0 & 0 \\
\hline case 3 & 0 & 1 & 1 & 0 & 1 & 0 \\
\hline case 4 & 0 & 1 & 0 & 1 & 1 & 0 \\
\hline
\end{tabular}

The intersection of all winning coalitions is called a veto coalition; without the agreement of all of the individuals of the veto coalition, no statement is accepted by the group. As a consequence of the previous proposition, the veto coalition is a winning coalition, and by construction the only minimal winning coalition of a logically consistent game. We can obtain more: the veto coalition consists of only one individual, a dictator. Such a game is called dictator game. If $i$ is the dictator, the following formula holds

$$
v(S)=1 \text { if and only if } i \in S .
$$

Proposition 3.4. A rule of aggregation that preserves both the negation and the implication induces a dictator game.

Proof. Let $\mathrm{S}$ denote the veto coalition, i.e. the intersection of all winning coalitions. Select $i \in S$; the coalition $N-\{i\}$ is not winning. By the constant-sum property, the coalition $N-S+i$ is winning. Since the intersection of winning coalitions is a winning coalition, too, we get

$$
\{i\}=S \cap(N-S+i)
$$

as a winning coalition. Hence individual $i$ is the only element of $S$.

The existence of a dictator can be seen as a rigorous negation of the symmetry condition. Following this idea, we can state the following as a rigorously weakened symmetry condition:

There should be no dictator.

Remember that super-additivity, which is still consistent, is a weaker requirement than the constantsum property which corresponds to the preservation of the negation. If we do not want to renounce consistency and preservation of implications, then whenever $[a]$ and $[b]$ are winning coalitions, the coalition $[a] \cap[b]$ is winning too. Therewith the following can be shown:

Proposition 3.5. The only symmetrical, contradiction free and implication preserving aggregation rule is the unanimity rule (unanimity in $N$ ).

\footnotetext{
${ }^{10}$ This condition of the closed domain can be weakened.
} 


\section{DOMAINS OF ALTERNATIVES AND JUDGEMENTS OF PREFERENCE}

\subsection{BORDA UND CONDORCET}

In 1951, Arrow's book Social Choice and Individual Values was published. The analysis of possible aggregation methods for preference orderings contained therein had important effects on all social sciences, far beyond welfare economics. At that time, formalisms that were to explain economic actions as derived from some preassumed preferences (or utility functions) of the individual actors had entered into mainstream of economic thought; moreover these ideas had become predominant.

Considering preference judgements instead of more general (logical) statements, it seems obvious that it is sensible to condense the information of a large set of single "atomic" preference statements like "alternative $\mathrm{x}$ is better than $\mathrm{y}$ " into a preference relation or function characterising every individual; then, the relation or function generates all single statements. In this approach, the task of aggregation changes. The questions are: How can a set of individual preference relations be aggregated into one preference relation characterising the group (for functions we get the question respective), and can it be done in a satisfactory way?

Let $X$ be a finite set of alternatives and $\# X=m$, the number of its elements. As possible preference relations, let us consider the set $\operatorname{ord}(X)$ of (strict) orderings on $X$, i.e. binary relations, that are transitive, asymmetric, and complete. ${ }^{11}$ We can identify these orderings with the set of permutations. Hence, there are $m$ ! such orderings. Some other types of preferences are found in the literature; for example, the formalisation as a set of reflexive, transitive, and complete relations (Arrow), as a set of reflexive, transitive, and antisymmetric relations (Debreu), etc. All these models agree on the main conclusions, but the notation for the model based on orderings is the simplest; hence we restrict our presentation to preferences modelled as orderings. A further advantage of this approach is that we can easily compare it with the work of Condorcet and Borda.

Orderings on $\mathrm{X}$ generate a set of expressions that is spanned by atomic terms $x>y$ (given $x, y \in X$ and $x \neq y$ ), i.e., all other elements of this domain are built combining such atomic expressions by logical operations. From the properties of orderings (transitivity, asymmetry, completeness), it is possible to conclude that it is not possible to freely assign truth values to atoms: There is some logical interdependence.

The question of how preferences should be aggregated was motivated by problems that arise if there is a choice between more than two alternatives. In the political context such alternatives are often alternative candidates. A voting rule is a mapping

$$
f:(\operatorname{ord}(X))^{N} \rightarrow X:\left(>_{i}\right)_{i \in N} \mapsto x
$$

Mappings that aggregate individual orderings by

$$
f:(\operatorname{ord}(X))^{N} \rightarrow \operatorname{ord}(X):\left(>_{i}\right)_{i \in N} \mapsto>
$$

are called social welfare functions. A N-vector of orderings, i.e. an element of $(\operatorname{ord}(X))^{N}$ is called an order profile.

In the year 1770, Borda (cp. Borda 1784) had reported that simple majority rule may lead to the selection of a candidate who performs worse in all pairwise comparisions with other candidates (Borda effect).

\footnotetext{
${ }^{11}$ Consider a binary relation $>$ on $X$. The relation is transitive, when $x>y$ and $y>z$ implies $x>z$ for all $x, y, z$; the relation is asymmetric if $x>y$ implies that $y>x$ is not true; the relation is complete if $x>y$ or $y>x$ for all $x, y$.
} 


\begin{tabular}{|l|c|c|}
\hline Voters & Preference & $\#[y>x$ and $z>x]$ \\
\hline $1-8$ & $x>y>z$ & 0 \\
$9-15$ & $y>z>x$ & 7 \\
$16-21$ & $z>y>x$ & 6 \\
\hline
\end{tabular}

Bordas analysis is based on pairwise comparisons, i.e. we ask " $x>$ y or $y>x$ ". Responses are collected and aggregated by majority rule. We get $x>y$ if and only if $\#[x>y]>\#[y>x]$ (this is Borda'a approach) or $x>y$ if and only if \#[x>y]> $\frac{n}{2}$ (what is used by Condorcet). These definitions are not really equivalent. The first relation is called a Condorcet relation. Condorcet considers a rich collection of examples. A famous demonstration is an example of an order profile wherein the top element of its aggregate, according to the Condorcet relation, ${ }^{12}$ gets the smallest number of direct votes (plurality rule).

Condorcet's most famous demonstration is that the aggregation by majority rule may lead to cycles of atomic expressions like $x>y, y>z, z>x$, resulting in a relation $>$ that is not an ordering. Such cases are said to show the Condorcet effect. And in some of these cases (when cycles are found at the top of the relation), there is no Condorcet winner. The following table demonstrates the simplest case.

\begin{tabular}{|l|l|}
\hline voter & preference \\
\hline 1 & $x>y>z$ \\
2 & $y>z>x$ \\
3 & $z>x>y$ \\
\hline
\end{tabular}

For those who only intend to select a best candidate, it would be good news if there were no Condorcet winner for only a few order profiles - but this is not the case. Let $\mathrm{m}$ be the number of alternatives. For $\mathrm{m}=3$ and $\mathrm{n}=3$ voters, we get 12 of the possible $216(=5,6 \%)$ cases in which there is no winner. Garman and Kamien (1968) showed the size of this share slightly increases when there is a larger number of voters. But the number of critical cases increases remarkably if the number of candidates is increased.

\begin{tabular}{|l|c|c|c|c|c|c|c|c|c|}
\hline $\mathrm{n}$ & 1 & 3 & 5 & 7 & 9 & $\ldots$ & 25 & $\ldots$ & $\infty$ \\
\hline$\%$ & 0 & 5,6 & 7,0 & 7,5 & 7,9 & $\ldots$ & 8,4 & $\ldots$ & 8,8 \\
\hline
\end{tabular}

Consider $n \rightarrow \infty$ and the variation of $\mathrm{m}$. We get the following limits (Niemi/Weisberg 1968; the limiting case of infinite spaces of alternatives was studied by Rubinstein 1979).

\begin{tabular}{|c|c|c|c|c|c|c|c|c|c|c|}
\hline $\mathrm{m}$ & 1 & 2 & 3 & 4 & 5 & 10 & 2 & 30 & 40 & $\infty$ \\
\hline$\%$ & 0 & 0 & 8,8 & 18 & 25 & 48 & 68 & 76 & 80 & 100 \\
\hline
\end{tabular}

If the domains of the alternatives are endowed with additional structure and suitably connected with the possible preferences, the existence of a Condorcet winner may be guaranteed. Moreover, under some circumstances (we deal with them later), the aggregation of the individual judgements yields an ordering.

Borda detected that it is possible to circumvent the difficulties with the task to aggregate individual orderings into a common ordering. He proposed that every voter should rank order the candidates according to her or his preferences and should represent this judgement by the ranking numbers (using the highest score for the most preferred candidate). Borda's rule sums up the individual ranking numbers for each candidate. The candidate exhibiting the largest sum is selected (in case of ties, an additional rule may select the "best").

\footnotetext{
${ }^{12}$ If there is a unique element on the top of the Condorcet relation, an element preferred against any other, such an element is called Condorcet winner.
} 
The work of Black (1948) and Arrow (1951) initiated and motivated new research on aggregation rules, developing a rich literature. With respect to voting rules, substantial advances have been made for Condorcet-type rules ("Condorcet consistent rules") and Borda-type rules ("scoring methods"). Due to their favourable properties, they are preferred. A comprehensive synopsis is given in Moulin (1988, ch. 9).

\subsection{ARROW'S IMPOSSIBILITY THEOREM}

In the following we focus on the aggregation of orderings, leaving the voting rules largely unconsidered. The most popular result in this field is Arrow's impossibility theorem. The theorem states that in case of more than two alternatives, it is impossible to construct a social welfare function rule that simultaneously entails the following properties (cp. Sen 1968):

(P) Pareto principle (or unanimity): if $[x>y]=N$, then $x>y$.

(IIA) Independence from irrelevant alternatives: if there is coincidence in the comparison of one single pair of two different order profiles, both the aggregate judgements coincide in the comparison of this pair of alternatives. This property means that the collective judgement comparing some alternatives is not dependent on other alternatives.

(nD) Non-dictatorship. There is no individual $\mathrm{i}$, whose preference ordering $>_{i}$, coincide with the collective ordering $>$ for all order profiles $\left(>_{i},\left(>_{j}\right)_{j \in N-\{i\}}\right)$.

There are a large number of variants of this theorem. For example, one may allow for indifference about alternatives (see Arrow 1951, Moulin 1988, pp.289f). The proof is analogue to the considerations in Section 2 and uses the property IIA to limit the necessary considerations: thereby it is enough to deal with few atomic expressions $x>y$ and coalitions $[x>y]:=\left\{i \in N ; x>_{i} y\right\}$. Since orderings are transitive and complete, from the validity of a set of atomic expressions, we can conclude that some other expressions are true. The properties of the aggregate relation can be translated as follows:

- Completeness: if $x \neq y$, then either $x>y$ or $y>x$; with respect to the corresponding coalitions, we get $[x>y]+[y>x]=N$.

- Transitivity: if $x>y$ and $y>z$, then $x>z$; with respect to the corresponding coalitions, we get $[x>z] \supset[x>y] \cap[y>z]$.

Such a translation of completeness and transitivity correlates to the preservation of the negation and of the implication discussed in Section two. Analoguesly also for aggregating preferences, in order to prevent inconsistent results, we will get a dictator.

A coalition $\mathrm{S}$ is called decisive for some ordered pair of alternatives (x,y) if and only if $S=[x>y]$ implies $x>y$ for all order profiles in $\operatorname{ord}(X)^{N}$. The set of coalitions decisive for $(x, y)$ is denoted by $W(x, y)$. This set of coalitions can be interpreted as the winning coalitions of a game $(N, v), v=v(x, y)$. Remarks: Under the condition (IIA), a coalition $S$ is decisive for $(x, y)$ if and only if there exists an order profile such that $S=[x>y], x>y$ is fulfilled. A coalition $S$ which is decisive for $(x, y)$ is decisive for $(y, x)$ too.

Proposition 4.1. If properties (P) and (IIA) hold, then $W(x, y)=W(w, z)$ for all $w, x, y, z \in X$.

Remark: In other words, every pair generates the same game.

Proof. Fix some $\mathrm{x}$ and $\mathrm{y}$. Let $T \in W(x, y)$. 
1. We show $T \in W(x, z)$ for all $z \neq x$.

Consider an order profile such that $T=[x>y>z]$ and $N-T=[y>z>x]$. According to the preconditions, we have $x>y$. We get $y>z$ by unanimity and $x>z$ by transitivity.

Since $T=[x>z]$, we get $T \in W(x, z)$.

2. We show $T \in W(w, z)$ for all $w, z \neq x$.

Consider an order profile such that $T=[w>x>z]$ and $N-T=[z>w>x]$.

$x>z$ holds because of $T \in W(x, z)$. We get $w>x$ by unanimity and $w>z$ by transitivity.

Since $T=[w>z]$, we get $T \in W(w, z)$.

3. It remains to show: $T \in W(w, x)$ for all $w \neq x$.

Consider an order profile such that $T=[w>z>x]$ and $N-T=[z>x>w]$.

$w>z$ holds because of $T \in W(w, z), z>x$ by unanimity and $w>x$ by transitivity.

Since $T=[w>x]$, we get $T \in W(w, x)$.

\section{Proposition 4.2. If property $(P)$ and (IIA) are fulfilled, then $(n D)$ cannot hold.}

Remark: In other words, under the condition (P) and (IIA), we get a dictator.

Proof. The previous proposition states that pairwise comparisons are aggregated by a unique game. Let $\mathrm{T}$ be a minimal winning coalition of that game. Assume that $\mathrm{T}$ contains more than one element. In this case, we can decompose $\mathrm{T}$ into two disjoint coalitions, $T_{1}$ and $T_{2}$. Consider the following order profile: $T_{1}=[x>y>z], T_{2}=[y>z>x]$, and $N-T=[z>x>y]$. We get $T_{1}=[x>z], T_{2}=[y>x]$, and $N-T=[z>y]$. The coalitions $T_{1}$ and $T_{2}$ are not winning, otherwise $T$ would not be minimal. Since $\mathrm{T}$ is winning, its opposite $\mathrm{N}-\mathrm{T}$ is not winning. In total we get $z>x, x>y$, and $y>z$. This is contrary to transitivity. Thus coalition $\mathrm{T}$ contains only one individual, the dictator.

In 1952 Granger called attention to the relation between the aggregation of preferences and logical aggregation (algebra of formulas generated by the atoms $x>y$ and the logical operators). From the viewpoint of logic as a result of (IIA) and (P) aggregation can be reached by considering pairwise comparisons and summing them up in a simple game. The rule of aggregation is logically consistent; hence the corresponding game exhibits a constant sum, and intersections of winning coalitions are winning too. Thus, on the one hand, the aggregate relation is guaranteed to build an order; and on the other hand, the game is dictatorial.

Not every rule of choice is generated by a binary relation. Sen (1970) reports the following example of a rule $\mathrm{C}$, which cannot be derived from any binary relation:

$$
\mathrm{C}(\{1,2,3\})=\{1\}, \mathrm{C}(\{1,2\})=\{2\}
$$

In order to test our idea of choice, consider the following question (Sen 1970, p.17):

If the world champion in some game is a Pakistani, do we know that she/he is champion in Pakistan too?

To get back to Condorcet and Borda: Both researchers decided to base choice on preferences and tried to aggregate them. The best choice is the optimal alternative according to the aggregate order. Both Borda and Condorcet insisted on guaranteeing equal treatment. The rule should be symmetric not only with respect to electors/deciders (often called anonymity) but also with respect to candidates (often called 
neutrality). Hence, as we have learned above, they had to sacrifice some logical consistency. Borda's solution forces the aggregate to become an order, renouncing on the IIA-property. Condorcet's solution excludes profiles that lack a proper aggregate. Both approaches have their own appeal (see Young 1975 and Moulin 1988, pp. 237-240 for the first solution; and May 1951 and Moulin 1988, p. $286 \mathrm{f}$. for the second solution).

\subsection{Structures ADMitTing PROPER AGGREGATES}

Black (1948) and Arrow (1951) published a well-known theorem on the possibility to aggregate preferences of a certain type. The theorem proves that in case of an odd number of individuals and "singlepeaked" 13 individual preferences with respect to the same order on the set of alternatives, transitivity of the Condorcet relation is guaranteed; in particular there is a Condorcet winner.

The theorem can be extended in multiple directions. ${ }^{14}$ It can be seen as a special case of guaranteeing a proper aggregate by selecting a subspace of preferences showing a property that refers to a specific structure of the space of alternatives. For many practical problems, it is plausible to make such assumption. For example, in location conflicts (with attractive objects), the individuals' preferences may be represented as utility functions proportional to the distances from their ideal points. Black and Arrow dealt with the one-dimensional version of this setting. Here we can think of a spectrum of political parties, which may be ordered from "left" to "right". Every individual of the electorate may determine his or her ideal place within the spectrum. The assumption is that the individuals' preferences will decrease with increasing distance to his or her ideal point. In all these location settings, one- or multi-dimensional preferences may be aggregated by a generalised median. But indeed there are other location conflicts, in which the utility increases with the distance from the reference point, which can be interpreted as a worst-case location: here in the normal case, a Condorcet winner does not exist.

\subsection{RULES THAT ARE STABLE AGAinst STATEGIC ACTS}

What are the circumstances that allow for election and decision methods that impede manipulation? It seems that Condorcet had some hope that the proper election and decision-making methods would help to install enlightened representatives and to find true and just solutions reflecting the common interest (l'interêt général). On the one hand, Condorcet demonstrates advantages of group judgements (derived from probability theoretical considerations, see below); on the other hand, he demonstrates the lack of a justifiable aggregate, as discussed above. The decision-makers Condorcet has in mind when he models the decision process are truth-oriented, and they strive for a just and fair solution. In contrast in our modern view, actors mainly are modelled as rigourously self-interested, lying, and manipulative if such a behaviour is thought to yield a benefit for themselves. Condorcet was not blind to these hurdles to collective action. Forging judgments was seen a fault of men or of institutions that oppress people, preventing them from receiving an education and holding them in dependency. At the time of Condorcet's writing, there was neither a mathematical tool to ask whether a rule sets incentives to cheat and deceive, nor was there was the widespread view of purely selfish members of a community. Nevertheless, the non-cooperative analysis of the Condorcet rule exposes the fact that, under the condition that we aggregate profiles which admit a Condorcet winner (which is to chose), there is no incentive to deviate from truely reporting one's own

\footnotetext{
${ }^{13} \mathrm{~A}$ preference is called single peaked if there is a unique optimal alternative with respect to preference order - let us call it "peak" - and the set of alternatives is linearly ordered in such a way that the peak alternatives divide the set into a lower part with an increasing preference and an upper part with a decreasing preference; one of the two parts may be empty.

${ }^{14}$ Nevertheless most extensions of Blacks theorem are available only under very restrictive conditions.
} 
judgements/preferences (under the assumption of an odd number of individuals; see Moulin 1988, Lemma 10.3, p. 263).

In order to specify the above statement, we consider the following definition of strategic dependency: Let $\mathrm{f}$ be a voting rule, a mapping, assigning an alternative $f\left(\left(>_{i}\right)_{i \in N}\right)=x \in X$ to each order profile $\left(>_{i}\right)_{i \in N}$. Assuming that the individual preferences are private knowledge only, individuals can freely chose the alternatives they will report. Hence an individual preference becomes a strategic variable, and individuals can try to state a preference deviating from their true preference, but suitable for realising some individual advantage.

Game-theoretically this situation is conceived as a triple $\left(N,\left(Y_{i}\right)_{i \in N},\left(u_{i} \circ f\right)_{i \in N}\right)$, a non-cooperative game, of which the first component is the set $\mathrm{N}$ of players, the second component is the collection of individual strategy spaces $Y_{i}=\operatorname{ord}(X)$, and the last component a collection of the individual utility functions $u_{i}(x)$ provided by the rank of alternative $\mathrm{x}$ with respect to the order $>_{i}$. Note that the utility functions $u_{i}$ are only determined up to an ordinal rescaling.

A rule $\mathrm{f}$ is said to be (individually) strategically vulnerable if and only if $\left(u_{i}\right)_{i \in N}$ is not a Nashequilibrium. ${ }^{15}$ In such a case, there is an individual $i$ and an alternative strategy $y_{i} \neq>_{i}$ for this individual such that $u_{i}\left(f\left(y_{i},\left(>_{j}\right)_{j \neq i}\right)\right)>u_{i}\left(f\left(\left(>_{k}\right)_{k \in N}\right)\right)$. This fact can be interpreted as an incentive for individual $i$ to misreport preferences (by reporting $y_{i}$ instead of the true preference $u_{i}$ ) in order to be better off, under the assumption that the partners will truely report their preferences. In fact, people may exaggerate how bad some alternative is that otherwise would have the chance to be collectively chosen. In a profile which is a Nash-equilibrium, there is no incentive for individual manipulations.

Other possible manipulations arise from coordinated behaviour. In such cases a coalition can become better-off by a mutual false report. In a case like that above (where there is a Condorcet winner and group size is odd), the rule "take the Condorcet winner" is even coalitionally (strategically) invulnarable.

Let us now return to settings in which all possible preferences on a given set of alternatives are admitted. The Theorem of Gibbard-Satterthwaite (Gibbart 1973, Satterthwaite 1975) states that under the assumption of at least three alternatives and all the possible preferences are admitted, a voting rule which is strategically invulnerable has to be dictatorial.

Now consider a rule which is strategically vulnerable (i.e. it lacks a Nash-equilibrium or at least a coalition-proof equilibrium). An individual or a coalition that has an incentive to misreport preferences may lack a guarantee that the advantage aspired to can be achieved. It may be possible that the other partners (the "opposition") prevent the realisation by deviating from true reports themselves. Thus, for an analysis, it is useful to explore what an individual or a coalition can guarantee alone.

A voting rule $f:(\operatorname{ord}(A))^{N} \rightarrow X$ is related to its companion game $\left(N, v_{f}\right)$, the winning coalitions of which are exactly those coalitions that can enforce any alternative. Formally ${ }^{16}$ we can write:

$$
v_{f}(S)=1 \Leftrightarrow \bigwedge_{a \in A} \bigvee_{y_{S}} \bigwedge_{y_{N-S}} f\left(y_{S}, y_{N-S}\right)=a
$$

If the voting rule is Condorcet consistent or a rule of Borda type, then the companion game is essen-

\footnotetext{
${ }^{15} \mathrm{~A}$ strategy vector is called a Nash equilibrium, if for all individuals the individual outcome cannot be improved by altering the strategy of respective individual.

${ }^{16}$ The formula is read as follows. For all $a \in A$ there exists a joint strategy $y_{S}$ of coalition $\mathrm{S}$ such that for all strategies $y_{N-S}$ of its opposition $N-S$ the following equation holds: $f\left(y_{S}, y_{N-S}\right)=a$.
} 
tially given by ${ }^{17}$ (Moulin 1988, p. 268):

\begin{tabular}{|l|c|c|}
\hline Typ & $v(S)=1$ & $v(S)=0$ \\
\hline Condorcet consistent & $\# S>\# N-S$ & $\# S<\# N-S$ \\
Borda type & $\# S>2 \# N-S$ & $\# S<2 \# N-S$ \\
\hline
\end{tabular}

According to such rules, we select a Condorcet winner or a Borda winner respectively. Consider the case of five individuals. Condorcet consistency results in the set of all three-person coalitions being minimal winning coalitions, whereas a Borda type rule selects all four-person coalitions.

Though a winning coalition can enforce every alternative, it is not clear if all of its members can find an alternative to agree upon. Thus it is useful to ask if there are alternatives such that no winning coalition has an incentive to turn it down. The respective solution concept core of the conflict choice ${ }^{18}$ is borrowed from co-operative game theory. This solution concept maps every conflict of choice, i.e. a triple $\left(X,\left(>_{i}\right), f\right)$ consisting of set of alternatives, preferences, and a voting rule, onto the set of alternatives such that there is no winning coalition that prefers another alternative. Formally we write:

$$
\operatorname{Core}\left(X,\left(>_{i}\right), f\right)=\left\{x \in X ; \bigwedge_{a \in X} v_{f}([a>x])=0\right\}
$$

Assessing every element of the core as a solution to the problem of aggregation, we interpret the condition of an non-empty core as the condition under which an aggregation of the preferences is possible.

It has been shown that the core of choice is non-empty for all possible order profiles ${ }^{19}$ if the set of alternatives is small when compared to the degree of similarity between the companion game and veto games; the larger the set of alternatives, the more similar to a veto game the companion game has to be. As the critical variable, we can identify the maximum variation of decisions of the different winning coalitions. Consider a veto game. The intersection of all winning coalitions of such a game is not empty. Thus the maximum variation of results is zero. In section 2.4 it was shown that veto games are needed in order to preserve the implication. In the case of a superadditive game, two winning coalitions have a non-empty intersection: some variation may occur, but this variation is limited in such a way that games of this kind preserve negation. A stronger limitation arises from the condition that every set of $\mathrm{k}$ winning coalitions has a non-empty intersection. Then, a set of $\mathrm{k}$ winning coalitions never shows totally divergent opinions. A classification of games of this kind was introduced by Post (1941); we will discuss his approach below.

Let us fix a game. Consider the maximum number $\mathrm{k}$ such that every set of $\mathrm{k}$ winning coalitions has a non-empty intersection (let us call this number the Post number of the respective game). Then either $k+1$ is the minimum number such that there exist $\mathrm{k}+1$ winning coalitions that have an empty intersection or the intersection of all winning coalitions is non-empty; in the latter case the game is a veto game. The number $k+1$ and $\infty$ in the veto game case is called a Nakamura number. Its reciprocal value is a measure for the maximum variation of the effective spectrum of opinions.

The main result is given by the following theorem (Nakamura 1975, Moulin p. 269):

\footnotetext{
${ }^{17}$ For coalitions in the range of $\# S=\# N-S$ and $\# S=2 \# N-S$, respectively, there is a variety of different solutions for "stand-offs".

${ }^{18}$ The notion of a core is justified, since we get the usual core of a simple game by inserting $\left\{x \in \mathbb{R}^{n} ; \sum\left\{x_{i} ; i \in N\right\}=1\right\}$ as the set of alternatives that can be decided upon (by winning coalitions); it is well-known that the core of veto-games is empty.

${ }^{19}$ Moreover, the aggregate relation generated by the companion game is acyclic.
} 
Proposition 4.3. The core of the conflict choice of all possible conflicts of choice with a fixed set of individuals, a fixed set of alternatives, and a fixed voting rule is not empty if and only if the Nakamura number of the companion game is larger than the number of alternatives.

Remark:

The above condition (the core of all possible conflicts of choice with a fixed set of individuals, fixed set of alternatives, and fixed voting rule is not empty) is often called the core stability.

The reciprocal value of the Nakamura number measures the maximum variation of the effective spectrum of opinions. In order to construct cycles of aggregated preference judgements that make it impossible to mark an optimal choice, a sufficient variation in the spectrum of effective opinions is needed. If there is no sufficient variation, then we can exclude coalitional strategic vulnerability too.

For equal treatment, we can aggregate by using the symmetrically weighted majority games $(\mathrm{q} ; 1, \ldots, 1)$. The Nakamura number $r$ of such a game is given by

$$
r \geq \frac{n}{n-q}>r-1
$$

From this formula, we learn that for $\mathrm{m}$ alternatives, core stability is reached only for a large majority of $\mathrm{q}$ votes. With increasing number of alternatives, the needed majority rapidly approaches unanimity:

$$
q>n \frac{m-1}{m}
$$

\section{ACCESS TO TRUTH - A CALCULUS OF PROBABILITIES}

A major driving force in Condorcet's project of the analysis and design of aggregation rules was the desire to help to get reason and truth accepted. Formally an aggregation of binary judgements took place. A modern view would assume a package of individual interests as the basis for the aggregation or for a reasonable compromise.

From the observation that reason cannot be guaranteed by the rule of aggregation alone, Condorcet infers that it is important to identify the additional conditions for getting optimal results. Reasoned dialogues that are not broken off so early that premature results are enforced are among the conditions he mentions. To establish such a favourable climate for discussions and decisions, the state has to create conditions for its citizens that allow for judging "by reason", "freely", and "independently". State respect and guarantees for human rights are among these conditions. It is especially important to abolish the paternalism of religious, political, and economic powers. The aim is to set humans free to find the "truth".

La vérité d'une décision dépend principalement de trois causes: des lumières et de la justesse d'ésprit des opinants, considérés individuellement; de la manière dont la discussion influe sur eux, soit pour leur donner de nouvelle lumières, soit pour les égarér; enfin, de l'influence plus ou moins forte des motifs étrangers à la vérité de la décision; influence qui peut ou séduire, ou faire agir de mauvaise foi. Il faut donc qu'une constitution remplisse les quatre conditions suivantes: que les votants soient éclairés; qu'ils ne soient ni corrompus, ni capables de se livrer à des préjugées conformes à leurs intérêts; que la discussion ne serve qu'à les instruire; que leurs préjugés ou leur corruption ne puissent trop influencer sur la décision. La première et la seconde condition dépendent da la manière dont ils sont élus; les deux autres de la forme 
de l'assemblée. C'est donc pour remplir ces deux conditions qu'elle doit être constituée.

(Examen sur cette question, Euvres, t. 9, p. 338)

The world does not just laugh when a committee makes logically inconsistent decisions, but also when there is err about facts, especially when well-known even by children. In 1897 the House of Representatives of Indiana unanimously decided that the number $\pi$ has value 3.2. Evidently using the rule of aggregation in order to find the truth, we can get wrong results. A single human may err, committees too. In this context Condorcet raises the question, how probable an erroneous aggregate judgement is if majority rule is applied.

A well-known result of the respective inquiries of Condorcet is called the Condorcet Jury Theorem (Essai, pp. 3-14, 1785). A modern version of it is given by Owen/Grofman/Feld 1989:

Proposition 5.1. Let $n$ be odd. The individual access to truth is represented by a random variable admitting values 1 ( $=$ is right) and $0(=i$ is erronous $)$. It is assumed that all these random variables are independent of each other. Under the condition that all members of the group exhibit the same probability $p$ of error and the decision is made by majority, the following holds: the probability $P$ of an error of the aggregate (of an erronous decision of the group) decreases strictly for $p<\frac{1}{2}$ and increases strictly for $p>\frac{1}{2}$ with increasing group size. The respective limiting values for $n \rightarrow \infty$ are 0 and 1 .

Note that if the group contains one member only, then $\mathrm{P}$ and $\mathrm{p}$ coincide. Using an arbitrary simple game $(N, v)$ as a device for aggregating the values $x_{i}$ of the random variables $X_{i}, i \in N$, the aggregate random variable $v\left(\left(X_{i}\right)_{i \in N}\right)$ provides the truth value of the aggregate opinion. There are other interpretations of such a structure. In reliability theory and quality control, the game represents the connectivity in a system. The random variable $v\left(\left(X_{i}\right)_{i \in N}\right)$ represents the reliability of the systems output, which is dependent on the reliabilities $X_{i}$ of the components $i \in N$.

Generalisations of the above Jury Theorem are sought. On the one hand, one can abstain from the independent access to truth; and on the other hand, from the uniformity of individual probabilities of error. Condorcet discussed both generalisations (limited to the majority rule) in detail $;{ }^{20}$ his argumentation is mainly by examples, but there are analytical parts too (Essai, pp. 248-251, and Essai, pp. 252-255, 259264, respectively).

To my knowledge, such research is resumed only about 50 years later. In the year 1838, Poisson presented the book Recherche sur la probabilité des jugements en matière criminelle et en matière civile, précédés des règles générales du calcul des probabilités, which emphasizes that court judgements have to consider the evaluation and aggregation of testimonies.

Lacking the uniformity of access to truth, majority rule may provide strange results. Respective examples can be found in Groffman/Owen/Feld (1983) and Owen/Groffman/Feld (1989). A group of three individuals are endowed with the following probabilities of error $p_{1}=0.72, p_{2}=0.72, p_{3}=0$. The mean error is $\bar{p}=0.48$, but after aggregation we get an aggregate error of $P=0.52$. In the mirror case $p_{1}=1$, $p_{2}=0.28, p_{3}=0.28$, we get an aggregate error of $P=0.48$ (mean error is $\bar{p}=0.52$; note that the first group member is certain to show a false judgement). The above authors prove that the basic statement of the Condorcet Jury Theorem is preserved: with increasing group size, the aggregate error converges to 0 $(\bar{p}<0.5)$ and 1 respectively $(\bar{p}>0.5)$.

If individual judgement is not guaranteed to be independent, the mathematical analysis becomes much more difficult (Ramamurthy/Parthasarathy 1988). For the most part, only simple special cases are considered, like the existence of public opinion leaders.

\footnotetext{
${ }^{20}$ The respective Essai contains more than 300 pages and an introduction of more than 100 additional pages.
} 


\section{ADD-ON SIMPLE GAMES}

\subsection{BLOCKING, DUAL GAME AND CONSTANT-SUM EXTENSION}

The application of simple games devised here aims to put a group in the position to decide on "sentences". Should the group be a jury, the goal may be to get a common evaluation of the testimonies. For a parliament, it may be to enact a law. Yet in all cases, rules of aggregation distribute power that may be used by interested people. Cooperation in suitable coalitions provides the power to enact a certain proposition. Moreover, cooperation in other suitable coalitions may provide the power to avert it. In the following, we deal with such preventative power, called blocking power.

Consider a constant-sum simple game: then the decision-making power and blocking power coincide.

Fix a game $(N, v)$. The game $\left(N, v^{*}\right)$, defined by $v^{*}(S)=1-v(N-S)$, marks exactly those coalitions as winning which have blocking power in $(N, v)$. The game $\left(N, v^{*}\right)$ is called the game dual to $(N, v)$ or simply the dual game (if confusion is excluded).

Consider the duality, i.e. the mapping $*: v \rightarrow v^{*}$. It fulfills $\left(v^{*}\right)^{*}=v$. The set of constant-sum games contains "self-duals", i.e. games in which $v=v^{*}$ for the definition of duality implies $v(S)+v(N-S)=1$.

The dual nature of a weighted majority game is easy to determine. Let $\left(\lambda ; m_{1}, m_{2}, \ldots, m_{n}\right)$ be a representation of the weighted majority game $(N, v)$. Then, $\left((1-\lambda)+\sum_{i} m_{i} ; m_{1}, m_{2}, \ldots, m_{n}\right)$ is a representation of $\left(N, v^{*}\right)$.

As we have discussed in Subsection 2.2, the constant-sum property is desirable in some decision scenarios. If a superadditive game is given, then by adding a player and adding the blocking coalitions expanded with this new player to the set of winning coalitions, we get a constant-sum game. Often the player added is called a chairman, because his or her vote breaks stand-offs.

Formally the constant-sum extension $(\hat{N}, \hat{v})$ of a superadditive game $(N, v)$ is defined by $\hat{N}=N \cup$ $\{n+1\}$ and

$$
\hat{v}(S)=\left\{\begin{array}{lll}
v(S) & \text { if } & n+1 \notin S \\
1-v(N-S) & \text { if } & n+1 \in S
\end{array}\right.
$$

Again for weighted majority games, it is easy to calculate the constant-sum extention. If $\left(\lambda ; m_{1}, m_{2}, \ldots, m_{n}\right)$ is a representation of $(N, v)$, then $\left(\lambda ; m_{1}, m_{2}, \ldots, m_{n}, 2 \lambda-1-\sum_{i} m_{i}\right)$ is a representation of $(\hat{N}, \hat{v})$.

\subsection{COMPosed GAMES Und Post's Classes}

We now consider the space of all simple games $\mathcal{V}$ (the players' set $N$ is finite of arbitrary size). A dummy is a player who is not member in any minimal winning coalition. Other players may not ask for the agreement of such a player, since such a vote would never move the aggregate decision.

In the following we use four operations called Post's operators, namely:

1. adding a dummy,

2. merging two players,

3. permuting the players' set, 
4. and the composition of the games.

Whereas the first three operators do not need a further comment, we have to elaborate on the last one. Let $\left\{N_{1}, N_{2}, \ldots, N_{m}\right), \# M=m$ be a partition of $N$, i.e. a decomposition of $N$ into $\mathrm{m}$ sets such that every two of them have an empty intersection. ${ }^{21}$ A number of games $\left(N_{1}, v_{1}\right),\left(N_{2}, v_{2}\right), \ldots,\left(N_{m}, v_{m}\right)$ are composed by the aggregating game $(M, w)$, resulting in a game $(N, v)$, which is given by:

$$
v(S)=w\left(S \cap N_{1}, S \cap N_{2}, \ldots, S \cap N_{m}\right)
$$

In short, the (characteristic function of the) game is written as $v=w\left[v_{1}, v_{2}, \ldots, v_{m}\right]$. The composition reflects a situation in which the group of decision makers is divided into $\mathrm{m}$ constituencies or districts, and the final decision is made by their representatives, who are bound by the votes made in the districts. A further application of the composition is a multiple-house parliamentary system endowed with an aggregating rule $w$ (for example, a motion has to pass both a House of Commons and a House of States or Cantons).

In order to demonstrate the mechanism of Post's operators, let us examine some example games. Let id denote the ("degenerate") game with one player only. Adding dummies to this game, we get games with a dictator.

The token maj denotes the game characterised by the minimal winning coalitions 110, 101, and 011; this game is the smallest constant-sum game. Merging two of the three players, we get the game et, endowed with a unique winning coalitition; this game is the smallest unanimity game. The constant-sum extension is not a composition of Post's operators. But let us note that $\hat{e t}=m a j$.

The game induced by the minimal winning coalitions 110 and 101 is called veto; permuting the players' set by the permutation $\alpha$, we get two more "versions" of veto; up to this operation, veto is the smallest game which shows a veto coalition that is not winning by itself.

The game induced by the minimal winning coalitions 10 and 01 is called vel; it is the dual to et.

Consider a parliamentary system with two houses, in which both houses have to agree to a proposal; then, in such a case, the game et is applied. Only in very few cases are composed games weighted majority games, even if composed of such a simple game as et. In Shapley's listing (Shapley 1962) of small simple games, we find the game et[vel,vel], an example of a game that is neither superadditive nor dual to a superadditive game (its dual is vel[et,et]); such a game cannot be a weighted majority game.

Following Post, we define a game as belonging to the class $\mathcal{F}^{k}$ if every set of $k$ winning coalitions has a non-empty intersection. The set of superadditive games can be identified as class $\mathcal{F}^{2}$. In Section 3.4 we defined Nakamura numbers; a game with a Nakamura number of $\mathrm{r}$ is an element of all classes $\mathcal{F}^{k}$ such that $k<r$. In this view, the Nakamura Theorem translates to

$$
\text { core stability is equivalent to } v \in \mathcal{F}^{\# A} \text {. }
$$

Let us supplement the definition of F-classes with the class $\mathcal{F}^{\infty}$ : a game belongs to this class if the interasection of all winning coalitions is not empty. This class provides a new subsumption for veto games. $^{22}$

The following Theorem of Post (1941) gives an insight into the structure of the space $\mathcal{V}$ of all simple games. The notation $\ll A \gg$ is used for the set of games that is generated by repeatedly applying Post's operations, starting with the set $A$.

\footnotetext{
${ }^{21}$ Such sets are called disjunct or disjoint.

${ }^{22}$ Consider the classical solution concept core for cooperative games. Then $\operatorname{Core}(v) \neq \emptyset \Leftrightarrow v \in \mathcal{F}^{\infty}$. is fulfilled. The set $\left\{x \in \mathbb{R}^{n} ; \sum\left\{x_{i} ; i \in N\right\}=1\right\}$ can be interpreted as set of alternatives.
} 
Proposition 6.1. Every subset of $\mathcal{V}$, which is closed with respect to all four Post operators, is found in the following listing:

- $\mathcal{D}=\ll i d \gg$

- $\mathcal{P}=\ll e t \gg$

- $\mathcal{P}^{*}=\ll v e l \gg$

- $\mathcal{C}=\mathcal{C}^{*}=\ll m a j 》$

- $\mathcal{F}^{\infty}=\ll$ veto $\gg$

- $\left(\mathcal{F}^{\infty}\right)^{*}$

- $\mathcal{F}^{k}, k \geq 2$

- $\left(\mathcal{F}^{k}\right)^{*}, k \geq 2$

- $\mathcal{V}$

The following relations are given:

- $\mathcal{F}^{2} \cap\left(\mathcal{F}^{2}\right)^{*}=\mathcal{C} \supset \mathcal{D}$

- $\mathcal{F}^{k} \supset \mathcal{F}^{k+1} \supset \mathcal{F}^{\infty} \supset \mathcal{P} \supset \mathcal{D}$

- $\left(\mathcal{F}^{k}\right)^{*} \supset\left(\mathcal{F}^{k+1}\right)^{*} \supset\left(\mathcal{F}^{\infty}\right)^{*} \supset P^{*} \supset \mathcal{D}$

Remark. The elements of the class $\mathcal{D}$ are dictator games. The elements of the class $\mathcal{C}$ are constant-sum games.

With respect to weighting majority games, we get:

Proposition 6.2. The set of weighting majority games is closed with respect to duality, adding dummies, permutations, merging, but it is not closed with respect to composition.

Let $\left(\lambda ; m_{1}, \ldots, m_{i}, \ldots, m_{n}\right)$ be a representation of a fixed game.

For a proof, realise that $\left(m(N)+1-\lambda ; m_{1}, \ldots, m_{i}, \ldots, m_{n}\right)$ represents its dual;

$\left(\lambda ; m_{1}, \ldots, m_{i}, \ldots, m_{n}, 0\right)$ represents the game enriched with a dummy;

and $\left(\lambda ; m_{1}, \ldots, m_{i}, \ldots, m_{n-2}, m_{n-1}+m_{n}\right)$ is the game in which the two last players are merged.

\subsection{RESSOURCES AND PROCESSES OF PRODUCTION}

An additional interpretation of a weighted majority game is motivated by the study of collective goods and of production processes. In this view, the representation $\left(\lambda ; m_{1}, \ldots, m_{i}, \ldots, m_{n}\right)$ refers to a production process in which a player i is endowed with $m_{i}$ units of a resource. In order to produce the collective good, $\lambda$ units of the resource are required. In analogy to such a production process, we can identify any game with a similar production function if we allow for multiple resources: 


$$
\left(\begin{array}{llll}
\lambda_{1} ; & m_{11}, & \ldots & , m_{1 n} \\
\lambda_{2} ; & m_{21}, & \ldots & , m_{2 n} \\
\vdots & \vdots & \ddots & \vdots \\
\lambda_{k} ; & m_{k 1}, & \ldots & , m_{k n}
\end{array}\right)
$$

The respective collective good is produced if, for all resources $j$, at least $\lambda_{j}$ units are inserted. The game et[vel,vel] is an example of a game with two resources; as we have shown above, it is not a one-resource game (= weighted majority game). To set a representation, let the first two players be endowed with one unit of the first resource each, and the last two players be endowed with one unit of the second resource each. The collective good is produced if a unit of both resources is inserted.

Remark. The main difference from composition is that, for a representation by resources, the players' set is not decomposed.

\section{AgGREGATION AND REPRESENTATION}

\subsection{Two TYPES OF AGGREGATION}

The rules of aggregation discussed above integrate individual judgements about propositions into a common evaluation of this proposition. Such propositions or statements may refer to properties of one or more objects. In the special case, the objects to refer to are the individuals themselves; a single individual may show the specific property (value 1) or not (value 0). Correspondingly, it can be asked if the group will inherit the property from its members. In other applications, one may refer to pairs, triples, quadruples, etc. of atomic objects. An example of the usage of pairs are preference comparisons like "alternative A is preferred to alternative B". In all cases, a rule aggregates the individual evaluations into one general judgement.

Two different types of aggregation are to be distinguished. The first type refers to aggregations of individual data into one datum of the same kind; the second type of aggregate represents the variety of data. So far we have dealt with the first type. Individual judgements or attributes are integrated into a judgement or attribute that also may assigned to an individual. As we have seen, given a plurality of propositions, objects or attributes may lead to difficulties in identifying a consistent aggregate.

For instance, given some variety of possible propositions under consideration, the assumption of logical consistency in individual judgements cannot justify the presupposition of the logical consistency of the general judgement unless a single member of the group is marked as a "dictator". A "dictator", according to the definition in the sections above (with only the exception in the probability section) is independent of and immune to the opinions of other members of the group. In practice, for management it would not be wise to constantly disregard the opinions of employees.

The interaction of a group with its environment may be modelled as a process in which the environment produces propositions which are to be evaluated by the individual members of the group and processed according to the structure of the group. Finally the group's aggregate answer is transfered to the environment as the "system's" reply. Acknowledging the logical difficulties discussed above, if the environment is rich enough to deliver a broader variety of propositions, then we have to develop different requirements for aggregates than for individuals. Also, empirically it can be observed that the behaviour of individuals conforms to different standards than the behaviour of groups. Such differences may not always have 
effects that favour individuals.

The second type of aggregation does not treat the aggregate as an individual. Instead, a comprehensive characterisation of properties under consideration is strived for. An aggregation of this type may be based on counting and measuring. The occurence of a property (or of some combinations of properties or of some extent of a quantitative property) often is represented by relative frequencies or weights. Here, individual opinions, evaluations or properties are summarised "as far as possible or needed". Such aggregations are oriented on the statistical viewpoint or a viewpoint that descibes some order in the variety.

In dealing with quantitative properties like individual body size, the aggregation of the first type may consist in assigning the arithmetic mean or the median as a property of the group. Such datum may be the datum of an individual. This changes if we simultaneously consider a set of properties. Properties may be correlated with each other (it is not possible to combine them freely); in such cases, the existence of such an individual may become impossible e.g. if the individual should simultaniously exhibit all means or medians respectively. These problems of "metric aggregation" have certain analogues to the discussed problems of logical aggregation. An aggregation of the second type, which take into account additional parameters or characteristics of the distribution, may help to find a more appropiate characterisation of the aggregate.

\subsection{REPRESENTATIVE, REPRESENTANCES AND REPRESENTATION}

Groups use structurally different methods to facilitate aggregation; as examples, consider the following four methods:

- suspension of "immature" or "contested" decisions

- introduction of a hierarchy

- multiple countersigns

- assignment of competences

Applying such methods, the group becomes organised.

Within a certain frame, a representative of an organised group can act in lieu of the group. In our context, a representative of a group for a certain class of statements has to judge all respective questions the same way the group would judge under the rule provided for this class.

A coalition $\mathrm{S}$ is called homogenious if and only if all members of the coalition have a uniform judgement of all propositions under consideration. If all possible evaluations of propositions of the domain A of rule $\mathrm{v}$ are present in a group, then sorting individuals according to opinion profiles results in individuals, i.e. the only homogeneous coalitions are singletons. In such a case, only a dictator can be a representative, and the game $\mathrm{v}$ is dictatorial. In the other case, if not all possible profiles are present, larger coalitions may be homogenious.

Groups that cannot be represented (with respect to their opinion or acting) by a single individual may be represented by a larger selection of individuals. In practical policy this possibility is employed if people elect members of committees and parliaments. Representatives are a tool in many organisations: a head of a department may represent that department; a deputy may represent his or her electoral district. In a well-defined domain, they can decide and act in lieu of the people or (sub-)organisation they represent.

The circumstances under which a committee is valued as representative for the whole are important. Beginning with a certain degree of organisation, larger groups are endowed with "instances", which - 
sometimes partially under competition - claim to be representative for the whole (in a given context). Such a "representation" (representatative unit, organ, agency) itself is a group endowed with a rule of aggregation. The members of such committees are called representatives, too, even if it is unclear whom or what they are really representing.

\subsection{Political REPRESENTATION}

Political science has its own and controversal literature on the subject of representation. Especially where normative evaluations of political systems are concerned, controversies are unavoidable. In the German post-war discussions (see Rausch 1968), guided by the norm of a representative parliamentarism, plebiscitarian elements of the constitution of the state have often been understood as incompatible with a representative system. There has also been a debate on the role political parties should play in the political system and especially in a representative system.

In contrast to those discourses, here we focus on the representativeness of the political groups and the choice procedures. In theory, there are two basically different approaches. One approach originates in the norm that a delegate should represent the entire group. The other approach is opposed to that, and maintains that a delegate should represent only that part of the group which has charged her or him. For the latter approach, different interpretations (according to different scenarios) are possible. For instance, a delegate may represent his or her voters, his or her district or simpy a political party. The idea of representation may also include the idea of acting on behalf of and in lieu of the (sub)group represented.

If one thinks of the people as (the only) sovereign, all political organs can be traced back to representations of the people: presidents, queens, "Reichsstände", committees, juries, parliaments, and whatever else. The representatives control a certain power; however, they hold it not for their own sake, but in lieu of others. There has to be some regulation on the extent of authorative power. The kind of regulation and inspection chosen can be very different, and they depend on the goal of the representation. Do representatives form a people in miniature or are they an elected aristocracy? Is the main task of the representation to establish a strong government, or is it concerned with the control and inspection of the government in the interest of the represented? Condorcet exposed such problems and was involved in the practical arrangement of a system of democratically selected representation. But there is no formal theory on how several instances interact with each other. Even now, such a theory is in its infancy.

Which measures are to be encountered in order to lead representatives to truely represent the represented people or units? During Condorcet's lifetime, the claim of repeated, free, secret, and equal elections had been asserted, the demands for women's right to vote, for the abolishment of slavery, and for the separation of powers. As reported in the first section, in Condorcet's view, this is not enough - not at all. He himself experienced how, after a democratic start, the revolution's leaders developed a thirst of power, leading them to enslave the people again. Many similar examples of the turn to terror after a liberation are known today.

Still in the year 1785 Condorcet was rather a democratic monarchist than a republican. He sets the discovery of the "truth" and the common interest (l'intérêt général) as the first priority. The task was to develop all resources needed for such a project. Education and free elections are seen as cornerstones of it. Presumably, he thought of his "midwifery" for the newborn revolution as providing assistance of the above kind.

In June 1793 an anonymous criticism of the outline of a new constitution was published (Aux citoyens français sur la nouvelle constitution. Ouvres, tome 12). Condorcet was identified as the author, and in July he was accused and pursued. He risked his life criticizing the new restrictions on the human and civil 
rights, and denounced the misuse of procedures (“... on parait craindre de donner au peuple trop de droits à exercer") and the vague and inconsistent promises made by the ruling party. It was not acceptable for him that the group which had won the power manipulated the people to decide on things which they had no knowledge about, and thus it became dirigible by intriguers. The test of impartiality, consultation, and assessment had become impossible. The freedom of press was abolished, and the rights of the delegates were limited. Condorcet was allerted to the attempt of a small group ("association particulière") to occupy all power. For the leaders in power, the following words were the most insufferable ones, totally intolerable:

N'oubliez pas ... et jugez ensuite si des hommes qui auraient cherché à préparer le piédestal d'un nouveau roi n'auraient pas voulu aussi un conseil exécutif ... qu'il fût plus facile de remplacer par un monarque, sans déranger aucun des autres ressorts de la machine politique. (p. 674)

He concludes the proclamation with following words:

Français, celui qui vous adresse ces réflexions vous devait la vérité, et il vous l'a dite. Il ne s'est point nommé, parce que la presse, comme la parole, a cessé d'être libre, et que votre intérêt exige de cacher à vos ennemis le nom de vos défenseurs. (p. 675)

The constitutional debates mentioned above have produced divergent answers. One difference, which exists mainly between continental Europe and the Anglo-Saxon countries, refers to the prevailing type of representation in parliaments. In continental Europe there was more effort to build committees in such a way that they model society in miniature. ${ }^{23}$

Since the parties play a priviliged rôle in the shaping of public opinion and in the legislative system, it is understandable that those with its opinions, preferences, and ties are represented proportionally to the strength of the political parties (inducing proportional representation in election systems). ${ }^{24}$ Here we cannot consider these problems (which concern the whole political system and its culture) more deeply because we have to come back to the core concern - i.e. the representability of a committee and its performance with respect to aggregation.

\subsection{REPRESENTATIVE COMMITTEES AND MINIMAL REPRESENTATIONS}

To determine a committee, which can reflect opinions and interests in a group, a citerion is needed to present the variation. It is often assumed that opinions and interests mainly are determined by regional districts or by political parties. The district or party becomes the main criterion used to represent the variety. Both districts and parties induce a partition among the group members.

In this coarse simplification the residential district or the vote for a party serves as a criterion for defining the respective classes of opinion and classes of interests that should be represented in parliament.

In our formalisation, the parliament is identified with a simple game, members, and a decision-making rule; it represents the whole group if, for the central propositions, the propositions under consideration the

\footnotetext{
${ }^{23}$ Considered more thoroughly, this is a fiction, and the effort to get to know the judgements of the citicens is limited; moreover, often there is major influencing and manipulation, but in principle it is not easy to act against the expressed will of the public or against the publicly declared or published will of a larger part of the population.

${ }^{24}$ The representation by parties was already criticised. Leibholz is a more prominent political theorist, who unrestlessly warned of the dangers of the self-expanding power of the parties, which may also act against "their own" delegates and "their" voters.
} 
winning coalitions correspond to the winning coalitions of the parliament. Analoguously to achieve representative committees in the parliament, they should meet the requirement of showing the corresponding "majorities" in both parliament and the committee.

In the following we represent this by referring to one criterion only. According to this criterion, $\mathrm{n}$ types are distinguished. Formally we use an equivalence relation $i \sim j$ in order to decompose the group into $\mathrm{n}$ "types of opinion" or "types of interest" $G_{1}, \ldots, G_{n}$. Such a partition $\left(G_{1}, \ldots, G_{n}\right)$ of the members of $(\mathrm{G}, \mathrm{g})$ induces a game $(N, \tilde{g})$ between types by

$$
\tilde{g}(S)=g\left(\sum\left\{G_{i} ; i \in S\right\}\right) .
$$

Such a game can be understood as a result of multiple mergers (which are Post operators). Since weighted majority games are closed to merging, we know the following:

Corollary 7.1. If the aggregation rule of the group $G$ uses a weighted majority game, then the game between types is a majority game too.

This fact results in an additional important consequence:

Corollary 7.2. If the (weighted majority) aggregation rule of a group gives equal weight to every vote, then there is a representative committee for this group in which every vote is equally weighted.

From what has been said above, we know that the game $(\mathrm{N}, \mathrm{v})$ between the types is a weighted majority game, for example, induced by $\left(\lambda ; m_{1}, \ldots, m_{i}, \ldots, m_{n}\right)$. In order to construct a representative committee in which all individuals are treated equally, let us fix the size of the committee by $m(N)=\sum\{m(i) ; i \in N\}$. Then, every type i gets $m_{i}$ members in the committee, endowed with one vote each. The voting threshold is $\lambda$, as before.

In game theory, a vector $\left(\lambda ; m_{1}, \ldots, m_{i}, \ldots, m_{n}\right)$ is called a representation of the game $(\mathrm{N}, \mathrm{v})$ if precisely the winning coalitions $\mathbf{S}(v(S)=1)$ are those coalitions for which $m(S) \geq \lambda$ is fulfilled.

In accord with the previous discussion, the analysis of parliaments and committees gains from the game theoretic notion of representation in a certain way. In our application, it is a game between types that represents the group. To represent the group, it has to be derived from a (game theoretic) representation of the basic game between all members of the group.

Let us now deal with some properties of games and their representations. First, we observe that a game admits either many representations or none. Let $\nu$ be a natural number and let $\left(\lambda_{1} ; m_{11}, \ldots, m_{1 n}\right)$ and $\left(\lambda_{2} ; m_{21}, \ldots, m_{2 n}\right)$ be representations of $(\mathrm{N}, \mathrm{v})$; then $\nu\left(\lambda_{1} ; m_{11}, \ldots, m_{1 n}\right)$ and $\left(\lambda_{1} ; m_{11}, \ldots, m_{1 n}\right)+$ $\left(\lambda_{2} ; m_{21}, \ldots, m_{2 n}\right)$ are representations too.

For example, the representations $(6 ; 5,3,2,1),(3 ; 2,1,1,1),(12 ; 10,6,4,2),(9 ; 7,4,3,2)$, and $(9 ; 7,2,3,4)$ represent the same game, a game called apex, the smallest one of the apex games, in which the strongest player can build a minimal winning coalition with each other player, and the coalition of all players except that strongest one is the only other minimal winning coalition.

If the parliament or committee is determined by election, then a proportional procedure induces representativeness. But in most cases, especially if the size of the "house" is fixed, the proportions cannot be guaranteed exactly; there are at least problems of rounding off. The properties considered and proposed by the theorists in the field of the respective procedures (procedures of apportionment; see Brams \& Straffin 1982) do not include representativeness. I consider this a major shortcoming in the theory. Up to now in the literature, the preservation of majorities has not been a focal point.

With a view to preserving majorities, the following procedure provides for representativeness and small houses: Based on the results of an election ("one man, one vote"), we consider the corresponding 
weighted majority game between the political parties. We determine the minimal representation, i.e. representation $\left(\lambda ; m_{1}, \ldots, m_{i}, \ldots, m_{n}\right)$ which minimises the number of "seats" $\sum_{i} m_{i}$ (such a minimal representation exists, but may be not unique). Every parliament or committee of size $k \sum_{i} m_{i}$, in which every party $i$ gets $k m_{i}$ representatives, mirrors the majorities in the electorate. Moreover, from the articles of Rosenmüller \& Sudhölter (1994), Sudhölter (1996), and Sudhölter \& Peleg (1998), it can be concluded that minimal representation is also a significant solution if we aim at distributional justice.

It is not always easy to find the minimal representation of a game. However, based on the list of all minimal winning coalitions for a subclass of games (called homogeneous weighted majority games; this class is large only for small numbers of players, say smaller than 11), there is a simple procedure to construct minimal representation (Ostmann 1987; here we also demonstrate that, for these games, there is a unique minimal representation).

Let us explain the procedure for determining the minimal representation with the help of a simple example. The following game is shown in the form of a matrix of the minimal winning coalitions. The players are numbered in such an order, with the stronger ${ }^{25}$ coming first. Then, the coalitions are given in rows, ordered lexicographically.

$$
\left(\begin{array}{lllll}
1 & 1 & 0 & 0 & 0 \\
1 & 0 & 1 & 0 & 0 \\
0 & 1 & 1 & 1 & 0
\end{array}\right)
$$

A player is designated as a step player if players weaker than himself cannot substitute for him. A player is designated as a sum player if, in some minimal winning coalition, a set of weaker players can substitute for him.

The rule of construction is as follows:

- Dummies get the weight 0 .

- Step players get 1 more than the available remains of weaker players.

- Sum players get the weight of their substitution set.

In our example we get the following calculations:

5: 0 (dummy), 4: 1 (step), 3: 2=1+1 (step), 2: as 3, 1: 3=2+1 (sum).

Thus, we get the minimal representation $(5 ; 3,2,2,1)$.

Consider now the results from the election to the German parliament (Bundestag) in the year 2005. The electorate established the following game between the parties:

$$
\left(1+\frac{45.430 .378}{2} ; 16.194 .665,13.136 .740,4.648 .144,4.118 .194,3.838 .326,3.494 .309\right)
$$

According to law, the Bundestag was determined as a house with 614 deputies. This induces the following game between the parties:

$$
\left(1+\frac{614}{2} \quad ; \quad 222 \quad 180 \quad 61 \quad 54 \quad 51 \quad 46\right)
$$

\footnotetext{
${ }^{25}$ Player $\mathrm{i}$ is at least as strong as player $\mathrm{j}$ if, for all winning coalitions $\mathrm{S}$, in which $\mathrm{j}$ is a member, the coalition $S-\{j\}+\{i\}$ is a winning coalition too.
} 
In our case, both games (electorate and Bundestag) coincide; representativeness is achieved. The minimal representation of the game is:

$$
\left(\begin{array}{llllllll}
5 & ; & 3 & 2 & 1 & 1 & 1 & 1
\end{array}\right)
$$

Collecting players of same strength, we get a more compact notation. The first line includes the numbers of parties with the same amount of strength; the matrix below reports the profiles of the minimal winning coalitions.

$$
\left.\left(\begin{array}{lll}
(1 & 1 & 4 \\
1 & 1 & 0 \\
1 & 0 & 2 \\
0 & 1 & 3
\end{array}\right)\right)
$$

The above game is not really a proper representation once one realises that a larger part of the electorate is not represented. To demonstrate we define the "neglected party/disregarded electors" (this party received $22,3 \%)$, the numbers of which are marked in bold below. We get:

$$
\left(0,5+\frac{60.859 .701}{2} ; 16.194 .665, \mathbf{1 4 . 4 2 9 . 3 2 3}, 13.136 .740,4.648 .144,4.118 .194,3.838 .326,3.494 .309\right)
$$

The minimal representation is:

$$
\left(\begin{array}{lllllllll}
8 & ; & 4 & 4 & 3 & 1 & 1 & 1 & 1
\end{array}\right)
$$

The condensed representation, noted by levels of strength is:

$$
\left.\left(\begin{array}{lll}
(2 & 1 & 4 \\
2 & 0 & 0 \\
1 & 1 & 1
\end{array}\right)\right)
$$

For proper representation in the parliament, we assign empty seats to the "neglected party". Then, we get the following representation:

$$
(8 ; \quad ; \quad 4 \quad 3 \quad 1 \quad 1 \quad 1 \quad 1)
$$

Since the large party lacks the neglected party as coalition partner, its strength is reduced to the middle level. The minimal representation is:

$$
(5 \quad ; \quad 2 \quad 2 \quad 11 \quad 1 \quad 1 \quad 1)
$$

This game is characterised by a veto coalition; the intersection of all winning coalitions is the coalition of the two big parties.

While the minimal representation above was used to judge the representativeness of a parliament, there is an further important use of minimal representation: the determination of seats in parliamentary committees. If a question is not supposed to be prepared and/or treated in the plenum, usually a committee is formed in which the parliamentary groups are to be appropriately represented. Representativeness - in the sense of a preserved game - is not yet an explicit goal either in theory or in the rules or parliamentary procedures (as in apportionment theory). In our view, we also have to question how large a committee has to be in order to allow for representativeness.

An obstacle to the application of the minimal representation may also be the practise of treating things that are governed by different rules within the same committee. Even when reduced to explicit decision making, there are different thresholds needed, for example, for investigations, for demanding information, for introducing a motion, etc. Under the condition of such multifunctionalities, parties that are dummies according to the main decision rule may have rights in regard to other items, which must not be neglected. 


\section{REFERENCES}

[1] Arago, M. F. \& O'Connor-Condorcet, A. (eds.) (1847-1849). Euvres de Condorcet. 12 volumes. Paris: Firmin Didot.

[2] Arrow, K. J. (1951). Social Choice and Individual Values. New York: Wiley.

[3] Beth, Th., Jungnickel, D. \& Lenz, H. (1985). Design Theory. Mannheim: Bibliographisches Institut.

[4] Borda (1784). Mémoire sur les élections au scrutin. Histoire de l'Académie des Sciences pour 1781. Paris.

[5] Brams, Steven J., and Philip D. Straffin, Jr. (1982). The Apportionment Problem (review of Balinski and Young, Fair Representation, Yale University Press, 1982). Science 217, no. 4558 (30 July): 437438.

[6] Brams, Steven J., Paul H. Edelman, and Peter C. Fishburn (2001). Paradoxes of Fair Division. Journal of Philosophy 98, no. 6 (June): 300-314.

[7] Brams, St. J. \& and Kaplan, T. R. (2005). Dividing the Indivisible: Procedures for Allocating Cabinet Ministries to Political Parties in a Parliamentary System. Universität Bielefeld. IMW working paper 340.

[8] Buffon (1777). Essai d'Arithmétique Morale.

[9] Condorcet. All citations except the Esquisse refer to the collected works edition: Arago, M. F. \& O'Connor-Condorcet, A. (eds.) (1847-1849) (Euvres).

[10] Condorcet, A. (1795). Tableau général de la science qui a pour objet l'application du calcul aux sciences politiques et morales. Tome 1 .

[11] Condorcet, A. (1785). Essai sur l'application de l'analyse à la probabilité des décisions rendus à la pluralité des voix. Tome 7.

[12] Condorcet, A. (1789). Essai sur les assemblées provençales. Tome 8.

[13] Condorcet, A. (1789). Examen sur cette question. Tome 9.

[14] Condorcet, A. (1793). Sur les élections. Tome 12.

[15] Condorcet, A. (1793). Esquisse d'un tableau des progres de l'esprit humain. New edition: Editions sociales,. Paris 1971.

[16] Cournot, A. A. (1838). Sur la probabilité des jugements. Journal de Liouville.

[17] Einhauser, R. (1898). Proportionalwahl. Zeitschrift für die gesamte Staatswissenschaft 54, 720-729.

[18] Edgeworth, F. Y. (1881). Mathematical psychics. London: Kegan Paul.

[19] Gibbard, A. (1973). Manipulation of voting schemes: a general result. Econometrica 41, 587-601.

[20] Granger, G.-G. (1956). La Mathématique Sociale du Marquis de Condorcet. Paris: Presses Universitaires de France. 
[21] Guilbaud, G. Th. (1952). Les Théories de l'interêt général et le problème logique de l'agrégation. Économies et Sociétés 5, 501-584.

[22] Jablonski, S. T. et al. (1970). Boolesche Funktionen und Postsche Klassen. Berlin (russian original: 1966, Moskau).

[23] Koyre, Alexandre (1948). Condorcet. Revue de Métaphysique et de Morale 53, 166-189.

[24] Laplace (1812). Essai philosophique sur les probabilités.

[25] Moulin, H. (1988). Axioms of cooperative decision making. Cambridge: Cambridge University Press.

[26] McLean, I. \& Hewitt, F. (1994). Condorcet: Foundations of Social Choice and Political Theory. Aldershot: Edward Elgar.

[27] Ostmann, A. (1985). Decisions by Players of Comparable Strength. Zeitschrift für Nationalökonomie 45, 267-284.

[28] Ostmann, A. (1987). On the Minimal Representation of Homogeneous Games. International Journal of Game Theory 16, 69-81.

[29] Ostmann, A. (1993). Simple Games: On Order and Symmetry. Note di Matematica 13, 251-67.

[30] Poisson, S.-D. (1837). Recherche sur la probabilité des jugements en matière criminelle et en matière civile, précédés des règles generales du calcul des probabilités. Paris: Bachelier.

[31] Post, E. L. (1941). The two-valued iterative systems of mathematical logic. Annals of Mathematical Studies 5.

[32] Rashed, R. (1974). Condorcet - Mathématique et Société. Paris: Hermann.

[33] Rausch (ed.) (1968). Zur Theorie und Geschichte der Repräsentation und Repräsentativverfassung. Darmstadt: WBG.

[34] Rosenmüller, J., and P. Sudhölter (1994). The nucleolus of homogeneous games with steps, Discrete Applied Mathematics 50, 53 - 76.

[35] Satterthwaite, M.A. (1975). Strategy-proofness and Arrow's conditions. Journal of Economic Theory 10, 198-217.

[36] Sen, A. K. (1968). Collective Choice and Social Welfare. Edinburgh: Oliver \& Boyd.

[37] Shapley, L. (1962). Simple Games. An Outline of the Descriptive Theory. Behavioral Science 7, 59-66.

[38] Sudhölter, P. (1996). Star-shapedness of the kernel for homogeneous games. Mathematical Social Sciences 32, 179 - 214.

[39] Sudhölter, P. \& Peleg, B. (1998). Nucleoli as maximizers of collective satisfaction functions. Social Choice and Welfare 15, 383-411. 
[40] Sudhölter, P. \& Peleg, B. (1999). Single-peakedness and coalition-proofness. Review of Economic Design 4, 381-387.

[41] Todhunter, I. (1865). A history of the mathematical theory of probability from the time of Pascal to that of Laplace. London: Macmillan.

[42] Wahlster, B. (1979). Condorcet. Esquise d'un tableau historique des progrès de l'esprit humain. Zur Entstehung des bürgerlichen Fortschrittsbegriffs. Zulassungsarbeit zum Staatsexamen. Universität Tübingen. 


\section{Max Planck Institute for Research on Collective Goods}

\section{Preprints 2007}

165. Frank P. Maier-Rigaud / Martin Beckenkamp, Purchase Decisions with Non-linear Pricing Options under Risk - Experimental Evidence. 2007/10.

164. Martin Hellwig, Switzerland and Euroland: European Monetary Union, Monetary Stability and Financial Stability. 2007/9.

163. Martin Hellwig, A Reconsideration of the Jensen-Meckling Model of Outside Finance. 2007/8.

162. Jörn Lüdemann, Netzwerke, Öffentliches Recht und Rezeptionstheorie. 2007/7.

161. Christoph Engel, Incentives for Process Innovation in a Collusive Duopoly. 2007/6.

160. Christoph Engel, Innovationsanreize aus Wettbewerb und Kollusion. 2007/6b.

159. Dorothee Schmidt, Mitigating the shadow of conflict - The role of social and human capital for the reduction of conflicts. $2007 / 5$.

158. Christoph Engel, Geistiges Eigentum als Anreiz zur Innovation - Die Grenzen des Arguments. 2007/4b.

157. Christoph Engel, Intellectual Property as a Carrot for Innovators. Using Game Theory to Show the Limits of the Argument. 2007/4.

156. Denise Bauer, Die Gesellschaft Bürgerlichen Rechts als Corporate Actor. 2007/3.

155. Martin Hellwig, A Contribution to the Theory of Optimal Utilitarian Income Taxation. 2007/2.

154. Christoph Engel, Competition in a Pure World of Internet Telephony. 2007/1.

\section{Preprints 2006}

153. Christoph Engel, How Much Collusion? A Meta-Analysis On Oligopoly Experiments. 2006/27.

152. Martin Hellwig, Incentive Provision with Hidden Characteristics: A Unified Approach. 2006/26.

151. Martin Beckenkamp, Heike Hennig-Schmidt, Frank P. Maier-Rigaud, Cooperation in Symmetric and Asymmetric Prisoner‘s Dilemma Games. 2006/25.

150. Felix Bierbrauer, Collectively Incentive Compatible Tax Systems. 2006/24.

149. Sven Fischer / Andreas Nicklisch, Ex Interim Voting in Public Good Provision. 2006/23.

published in:

Journal of Institutional and Theoretical Economics 2007, Vol 163 (1), 2007, 56-74.

148. Martin Hellwig, Private Damage Claims and the Passing-On Defense in Horizontal Price-Fixing Cases: An Economist's Perspective. 2006/22.

published in:

Jürgen Basedow (ed.), Private Enforcement of EC Competition Law, The Hague: Kluwer Law International, Den Haag, (2007) 121 - 159.

147. Martin Hellwig, The Provision and Pricing of Excludable Public Goods: Ramsey-Boiteux Pricing versus Bundling. 2006/21.

forthcoming in:

Journal of Public Economics 
146. Martin Hellwig, Effizienz oder Wettbewerbsfreiheit? Zur normativen Grundlegung der Wettbewerbspolitik. 2006/20. published in:

Christoph Engel/Wernhard Möschel (eds.): Recht und spontane Ordnung. Festschrift für

Ernst-Joachim Mestmäcker zum 80. Geburtstag. Nomos-Verlag Baden-Baden 2006, 231-268.

145. Christoph Engel / Elke U. Weber, The Impact of Institutions on the Decision How to Decide. 2006/19.

forthcoming in:

Journal of Public Economics

144. Felix Bierbrauer / Marco Sahm, Informative Voting and the Samuelson Rule. 2006/18.

143. Andreas Nicklisch. Perceiving strategic environments: An experimental study of learning under minimal information. 2006/17.

142. Felix Höffler: Mobile termination and collusion, revisited. 2006/16.

141. Ingolf Schwarz: Monetary Equilibria in a Baumol-Tobin Economy. 2006/15.

140. Martin Beckenkamp: The herd moves? Emergence and self-organization in collective actors. 2006/14.

139. Christoph Engel: Herrschaftsausübung bei offener Wirklichkeitsdefinition. Das Proprium des Rechts aus der Perspektive des öffentlichen Rechts. 2006/13.

forthcoming in:

Christoph Engel/Wolfgang Schön: Das Proprium der Rechtswissenschaft. Mohr (Siebeck) Tübingen 2007.

138. Christoph Engel: Wettbewerb als sozial erwünschtes Dilemma. 2006/12.

published in:

Christoph Engel/Wernhard Möschel (eds.): Recht und spontane Ordnung. Festschrift für Ernst-Joachim Mestmäcker zum 80. Geburtstag. Nomos-Verlag Baden-Baden 2006, 155-198.

137. Hendrik Hakenes / Isabel Schnabel: The Threat of Capital Drain: A Rationale for Public Banks? 2006/11.

136. Martin Hellwig: Zur Kategorie der Kausalität in den Wirtschaftswissenschaften. 2006/10.

135. Felix Höffler / Madjid Kübler: Demand for storage of natural gas in northwestern Europe. A simulation based forecast 2006-2030. 2006/9.

forthcoming in:

Energy Policy, 2007.

134. Dorothea Alewell / Andreas Nicklisch: Wage Differentials, Fairness and Social Comparison: An Experimental Study of the Co-Employment of Permanent and Temporary Agency Workers. 2006/8.

133. Stefan Magen, Zur Interaktion von Recht und sozialen Normen bei der dezentralen Bereitstellung von Gemeinschaftsgütern. 2006/7.

132. Felix Bierbrauer, Distortionary Taxation and the Free-Rider Problem. 2006/6.

131. Felix Höffler, Tobias Wittmann, Netting of capacity in interconnector auctions. 2006/5.

published in:

Energy Journal 2007, 28 (1), 113-144.

130. Eyal Ert / Andreas Nicklisch, Noisy commitments: The impact of information accuracy on efficiency. 2006/4.

129. Anne van Aaken, Begrenzte Rationalität und Paternalismusgefahr: Das Prinzip des schonendsten Paternalismus. 2006/3. published in: Christoph Engel/Markus Englerth/Jörn Lüdemann/Indra Spiecker: Recht und Verhalten. Mohr (Siebeck) Tübingen 2007, 189-230.

128. Jörn Lüdemann, Die Grenzen des homo oeconomicus und die Rechtswissenschaft. 2006/2.

published in:

Christoph Engel/Markus Englerth/Jörn Lüdemann/Indra Spiecker: Recht und Verhalten. Mohr (Siebeck) Tübingen 2007, 7-59.

127. Christoph Engel, The Difficult Reception of Rigorous Descriptive Social Science in the Law. 2006/1. 